\title{
Facile Electrochemical Synthesis of Pd Nanoparticles with Enhanced Electrocatalytic Properties from Surfactant-Free Electrolyte
}

\author{
Maksudul Hasan, ${ }^{*[a, b]}$ Worawut Khunsin, ${ }^{[c]}$ Christos K. Mavrokefalos, ${ }^{[a]}$ Stefan A. Maier, ${ }^{[c]}$ James F. \\ Rohan, ${ }^{[b]}$ and John S. Foord ${ }^{[a]}$
}

\begin{abstract}
Synthesis of low-dimension metallic nanoparticles of clean surface with high dispersibility and enhanced atomic surface distribution is extremely important since these strongly influence the electrocatalytic properties of the nanoparticles. In this study, the early stage electrochemical nucleation and growth of palladium nanoparticles ( $\mathrm{Pd} N \mathrm{NS}$ ) under potentiostatic control has been investigated on a $\mathrm{Au}(111)$ textured substrate. The size distribution and structural characterisation of the ex-situ as-deposited Pd NPs by means of high resolution Field Emission Gun-Scanning Electron Microscopy (FEG-SEM) at different stages combined with the electrochemical measurements revealed that cluster of nuclei grew independently by the reduction of metal ions. The electrodeposited $\mathrm{Pd}$ NPs were very pure as confirmed by X-ray Photoelectron Spectroscopy (XPS) due to the surfactant-free green electrodeposition process and highly dispersed with an average particle size $2-5 \mathrm{~nm}$. The average nanoparticle size becomes smaller with higher overpotential for the same deposition time. The synthesised Pd NPs demonstrated the largest specific surface area (4 times of commercial $\mathrm{Pd}-\mathrm{C}$ ) and the electrocatalytic activity in ferrocyanide/ferricyanide redox and ethanol electrooxidation processes (35 times of commercial Pd-C). This work represents an important step in achieving the fundamental understanding of nucleation and growth of nanoparticles correlating the electrocatalytic performances.
\end{abstract}

\section{Introduction}

Noble metal nanoparticles (NPs), usually in the size range of 10 $\mathrm{nm}$ and below exhibit superior electrocatalytic and electronic properties to their bulk counterparts due to unique shape, size and surface morphology. ${ }^{[1]}$ Palladium (Pd) NPs have received considerable interest in recent years due to their application in various electrocatalytic processes such as in organic synthesis, ${ }^{[2]}$ pharmaceutic, ${ }^{[3]}$ hydrogenation of polyunsaturated hydrocarbons, ${ }^{[4]}$ hydrogen storage ${ }^{[5]}$ bio/electrochemical sensors ${ }^{[6]}$ cancer treatment, ${ }^{[7]}$ fuel cells ${ }^{[8]}$ and co-catalysts in photocatalysis. ${ }^{[9]}$ Controlling the shape or surface of metal NPs

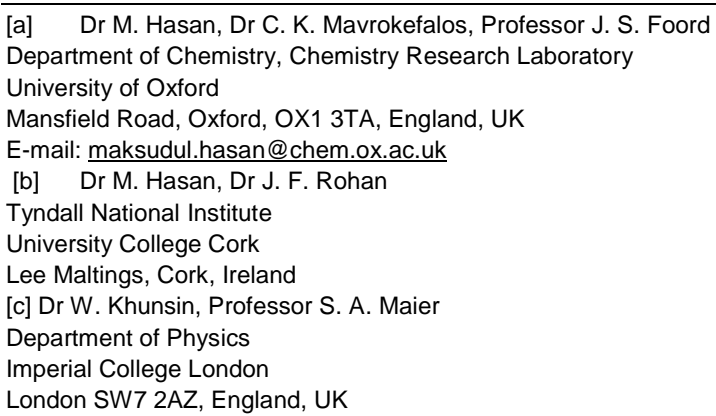

is crucial to their exploitation in specific applications from catalysis to chemical sensing to drug manufacturing. ${ }^{[1 a-c, 10]}$ To date, various synthetic approaches such as the reduction of metal salts or the decomposition of organometallic compounds have been investigated as feasible routes to the synthesis of noble metal NPs. ${ }^{[11]}$ Organic functional reagents such as polymers, surfactants and ionic liquids are generally used in these wet chemical syntheses to control the morphology, dispersibility and stabilisation of NPs in the homogeneous solution phase. The actual size of synthetic NPs varies from method to method since the final formation is not controlled by a single parameter, but instead the complex and combined effects of the surfactant, reducing agent, solvent, species concentrations, temperature and reaction time.

Another popular approach is known as seed-mediated growth, in which target NPs are grown from a solution of seeding NPs of a given crystallite or shape, metal precursor salt and a mild reducing agent. ${ }^{[12]}$ The seeding NPs reduce the metal species at the surface/solution interface with the help of a reducing agent. Recently, it has been reported that upon deposition ad-atoms may not remain on the same crystallite planes where deposition occurred but move to other crystallite planes due to self-surface diffusion processes. ${ }^{[13]}$ This phenomenon often disrupts the growth mode and hence, the final shape or morphology of the NPs. Although homogeneous dispersion of $\mathrm{Pd}$ NPs has been achieved in the seeding strategies or in some of the wet chemical synthetic methods referred to above, the capability to synthesise well-defined shape and highly dispersed Pd NPs of sub $10 \mathrm{~nm}$ dimensions is yet to be achieved. Additionally, advanced electrocatalysis/electroanalysis based on Pd requires Pd NPs in the conductive thin film format to miniaturise the overall electrode and device dimension particularly for handheld and portable devices. In particular, there has been increasing interest in the complementary metal-oxide-semiconductor (CMOS) compatible electrodeposition method that meets the underlined demand of synthetic Pd NPs with high dispersibility, large surface-to-volume ratio and enhanced atomic surface distribution. Among these, a direct electrodeposition method based on a sacrificial anode has been demonstrated to synthesise size-selective Pd NPs in an organic electrolyte. ${ }^{[14]}$ Under an applied current or potential, the bulk metallic Pd at the anode is dissolved as $\mathrm{Pd}^{2+}$ ions, which then migrate/diffuse to the cathode where they are reduced as ad-atoms. The size of the NPs can be controlled via a number of parameters such as solvent polarity, current density, charge flow, distance between electrodes, etc. ${ }^{[14 b]}$ This method was then further improved by the direct electroreduction of metal precursor salts in aqueous electrolytes i.e., metallic ions are directly provided by electrolyte rather than the sacrificial anode. ${ }^{[15]}$ Despite the improvement, there exists an inherent drawback with the method, i.e. two 
competitive processes occurring at the cathode; one is the reduction of metal ions as NPs and other is the reduction as a metallic film. ${ }^{[16]}$ To shift the balance in favour of NPs growth a surfactant is typically used to enhance the rate of NPs formation rather than the metallic thin film deposition. Also, the use of an ideal surfactant is crucial in stabilising the metal ions as nanocluster in the solution phase, which prevents precipitation as solid metal before the ions reach the cathode. The molecular nature of the surfactant, however, strongly affects the size and dispersibility of the synthesised metallic NPs. Moreover, it is not always possible to find a suitable surfactant for the specific sizeselective synthesis of metal NPs.

Here, we report a facile synthesis of Pd metallic NPs on Au substrate by electrodeposition from a surfactant-free green electrolyte. The growth modes of Pd NPs were analysed in detail and correlated with their electrocatalytic performance. The electrolyte consisted of $\mathrm{PdCl}_{2}$ as the precursor ion source in an aqueous and mild acidic environment at room temperature allowing sufficient time to form a ligand stabilised coordinated complex $\left[\mathrm{PdCl}_{4}\right]^{2-}$, in which $\mathrm{Pd}^{2+}$ ions were stabilised by the ligand effects of $\mathrm{Cl}^{-}$ions, or $\mathrm{H}_{2} \mathrm{O}$ or both depending on the electrolyte $\mathrm{pH}$. The effects of the applied overpotential and deposition duration were systematically investigated for their influence on the nucleation, growth and size of the Pd NPs, while other parameters such as precursor concentration and $\mathrm{pH}$ of the electrolyte were kept constant. A large potential window positive of the underpotential deposited hydrogen ( $\mathrm{H}_{\text {UPD }}$ ) was obtained for the electrodeposition of $\mathrm{Pd}$ through the $\mathrm{pH}$ dependent ligand coordination effects of $\mathrm{Cl}^{-}$and $\mathrm{H}_{2} \mathrm{O}$ with $\mathrm{Pd}^{2+}$ ions and, therefore, $\mathrm{Pd}$ NPs at a specific $\mathrm{pH}$ were deposited with a little influence of the $\mathrm{H}_{\text {UPD }}$ on growing $\mathrm{Pd}$ nuclei.

\section{Results and Discussion}

\subsection{Electrochemical deposition of Pd}

The $\mathrm{CV}$ of the $\mathrm{Au}(111)$ textured substrate was recorded in deaerated perchlorate $\left(\mathrm{HClO}_{4}\right)$ electrolyte containing chloride $(\mathrm{Cl})$ ions. The behaviour of $\mathrm{CV}$ (Figure S3a) is similar to the $\mathrm{Au}(111)$ surface and the peaks in the anodic scan corresponds to the structural transition of the Au(111) surface as discussed in the supplementary section. The (111) texture of the substrate was also confirmed by XRD analysis as discussed in section 3.3 . The $\mathrm{CV}$ in Figure 1a shows a wide onset potential region 0.7$0.27 V_{R H E}$ for $\mathrm{Pd}$ deposition well positive of the underpotential deposited hydrogen $\left(\mathrm{H}_{\mathrm{UPD}}\right.$ ) region which is found below 0.27 $\mathrm{V}_{\mathrm{RHE}}$. A cathodic current due to the reduction reaction 1 (below) started to flow around $0.7 \mathrm{~V}_{\mathrm{RHE}}$, followed by a substantial current rise to a maximum at $0.02 \mathrm{~V}_{\mathrm{RHE}}$ near the diffusion limited reduction of $\left[\mathrm{PdCl}_{4}\right]^{2-}$. No cathodic peaks for the underpotential deposition of Pd were observed. In another experiment, CV for the $\mathrm{Pd}$ deposition was conducted at slower scan rate of $1 \mathrm{mV} \mathrm{s}^{-1}$ from the same electrolyte (Figure S3b). The deposition peaks were similar to that of the higher scan rate and no cathodic peaks due to the underpotential deposition appeared at the potential more positive than $0.7 \mathrm{~V}_{\mathrm{RHE}}$. The current of $\mathrm{Pd}$ deposition (Figure 1a) decreases sharply beyond the peak at $0.02 \mathrm{~V}_{\mathrm{RHE}}$ as the mass transfer diffusion dominates, and reaches a minimum at $-0.002 \mathrm{~V}_{\mathrm{RHE}}$ followed by an increase due to the bulk hydrogen evolution. The potential region of 0.7-0.27 $\mathrm{V}_{\mathrm{REH}}$ is where the Pd metal deposition occurs without $\mathrm{H}_{\text {UPD }}$ and after this point deposition occurs simultaneously with $\mathrm{H}_{\text {UPD }}$ on the freshly deposited $\mathrm{Pd}$. As the cathodic potential limit gradually increases into the HuPD region, an anodic current due to Pd stripping at $0.98 V_{R H E}$ increases i.e., stripping current is linearly proportional to the overpotential indicating the deposition of $\mathrm{Pd}$ within the selected potential window. A pair of peaks $\left(C_{1}, A_{1}\right)$ appears (Figure $1 \mathrm{~b}$ ) as a result of the $\mathrm{H}$ adsorption $\left(\mathrm{H}_{\mathrm{ads}}\right)$ and desorption $\left(H_{\text {des }}\right)$, respectively, when voltammogram (D) was scanned negatively to $0.12 \mathrm{~V}_{\mathrm{RHE}}$. As the cathodic potential was scanned into and beyond the HUPD region, a sharp anodic peak appears at $0.11 \mathrm{~V}_{\mathrm{RHE}}$ (voltammetry $\mathrm{B}$ and $\mathrm{C}$ ) due to $\mathrm{H}$ absorption $\left(\mathrm{H}_{\mathrm{abs}}\right)$ onto the $\mathrm{Pd}$ lattice and its re-oxidation. In this overpotential region i.e. from 0.27 until $-0.08 V_{R H E}$, Pd deposition occurs simultaneously with $\mathrm{H}_{\mathrm{UPD}}$ as indicated by the appearance of a hydrogen desorption peak at $0.11 \mathrm{~V}_{\mathrm{RHE}}$ along with a larger $\mathrm{Pd}$ stripping peak at $0.98 \mathrm{~V}_{\mathrm{REH}}$ in the anodic scan. The higher anodic peak current for $\mathrm{Pd}$ striping indicates that $\mathrm{Pd}$ deposition increases as the overpotential increases and is not hindered by the HUPD. The higher cathodic current in the reverse scan for the potential region of 0.48-0.27 $V_{\text {RHE }}$ shown in Figure $1 \mathrm{~b}$ supports the fact that the deposition of Pd on Pd surface is faster than the nucleation on Au electrode surface.

$\left[\mathrm{PdCl}_{4}\right]^{2-}+2 e^{-} \rightarrow \mathrm{Pd}(0)+4 \mathrm{Cl}^{-}$

(1)

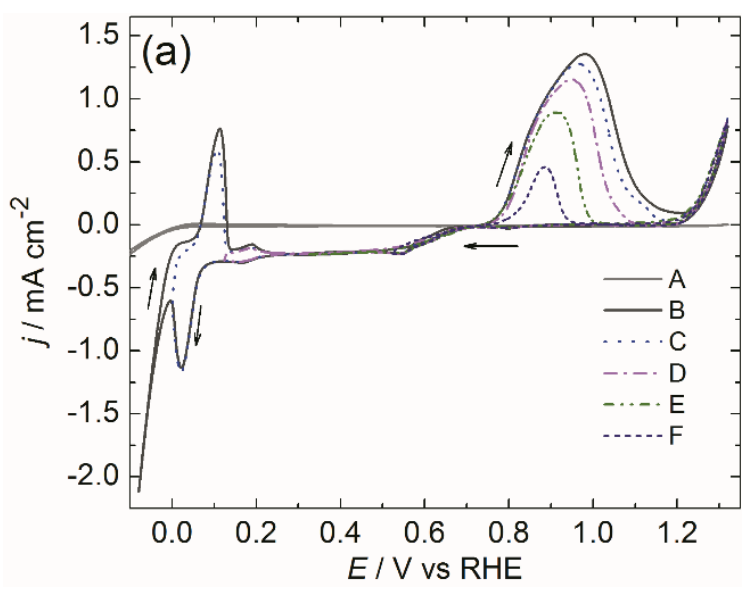




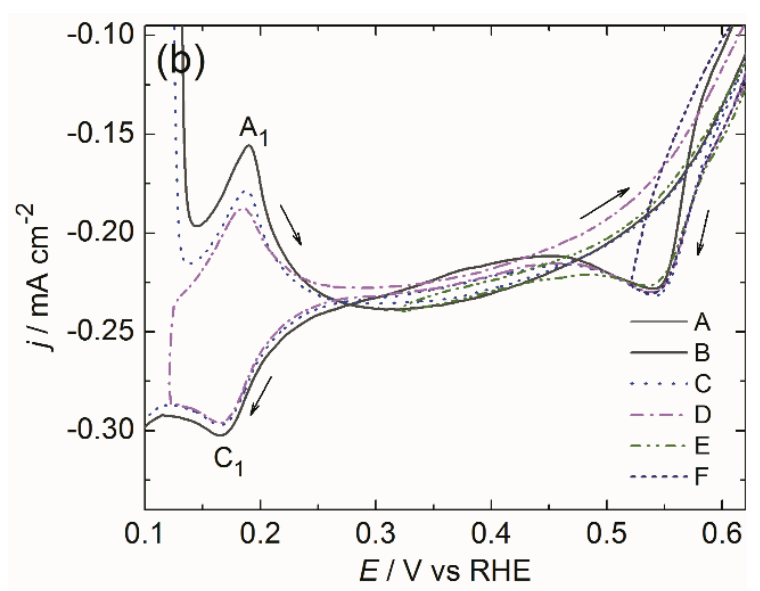

Figure 1. (a) Cyclic voltammetry of the Au substrate recorded in deaerated 0.1 $\mathrm{mol} \mathrm{L}^{-1} \mathrm{HCl}$ electrolyte containing $0.001 \mathrm{~mol} \mathrm{~L}^{-1} \mathrm{PdCl}_{2}$ scanned negatively from $\mathrm{OCP}$ with a scan rate of $5 \mathrm{mV} \mathrm{s}^{-1}$ (initial/conditioning: $0.79 \mathrm{~V}_{\mathrm{RHE}}, 10 \mathrm{~s}$ ), the upper potential limit was selected at $1.3 \mathrm{~V}_{\mathrm{RHE}}$ and reverse potential at 0.52 $\mathrm{V}_{\text {RHE }}(\mathrm{F}), 0.32 \mathrm{~V}_{\mathrm{RHE}}(\mathrm{E}) 0.12 \mathrm{~V}_{\mathrm{RHE}}(\mathrm{D}),-0.002 \mathrm{~V}_{\mathrm{RHE}}(\mathrm{C})$ and $-0.08 \mathrm{~V}_{\mathrm{RHE}}(\mathrm{B})$, where $A$ represents the voltammogram of the substrate in $0.001 \mathrm{~mol} \mathrm{~L}^{-1} \mathrm{HCl}$ electrolyte and (b) Expanded current densities within the selected potential region 0.1 to $0.6 \mathrm{~V}_{\mathrm{RHE}}$.

Three overpotentials were selected for the Pd deposition and named as small (0.54 $\mathrm{V}_{\mathrm{RHE}}$ ), medium (0.16 $\mathrm{V}_{\mathrm{RHE}}$ ) and large ($\left.0.002 \mathrm{~V}_{\mathrm{RHE}}\right)$ overpotential. The nucleation and growth of $\mathrm{Pd}$ at these selected overpotentials was investigated by potentiostatic transient measurement, in which $\mathrm{Pd}$ was deposited in a short pulse width of $5 \mathrm{~s}$ and stripped at $1.0 \mathrm{~V}_{\mathrm{RHE}}$, a potential sufficiently positive to ensure that no $\mathrm{Pd}$ remain on the surface. The current-time transients in Figure $2 \mathrm{a}$ shows an initial drop in cathodic current due to the adsorption and multistep charge transfer reactions and pass through a minimum to obtain the constant current values at longer deposition times. ${ }^{[17]}$ The last part of the current-time transient was used to plot steady-state current vs. inverse square root of the time in Figure $2 b$ since there is an important contribution of the adsorption current at the beginning of the deposition i.e. short time deposition. The resulting current-time transients recorded for the small, medium and large deposition potentials, all show the characteristic shape for an electrochemically driven, mass-transfer diffusion controlled (i.e., current is proportional to $\mathrm{t}^{-1 / 2}$ at long times), nucleation and growth process. ${ }^{[18]}$ The cathodic current is consistent with the Cottrelian decay indicative of the planar diffusion controlled growth. Thus, the selected overpotential region (i.e., small, medium and large overpotential) is large enough to overcome the potential barrier to nucleate the stable $\mathrm{Pd}$ nuclei for further growth.
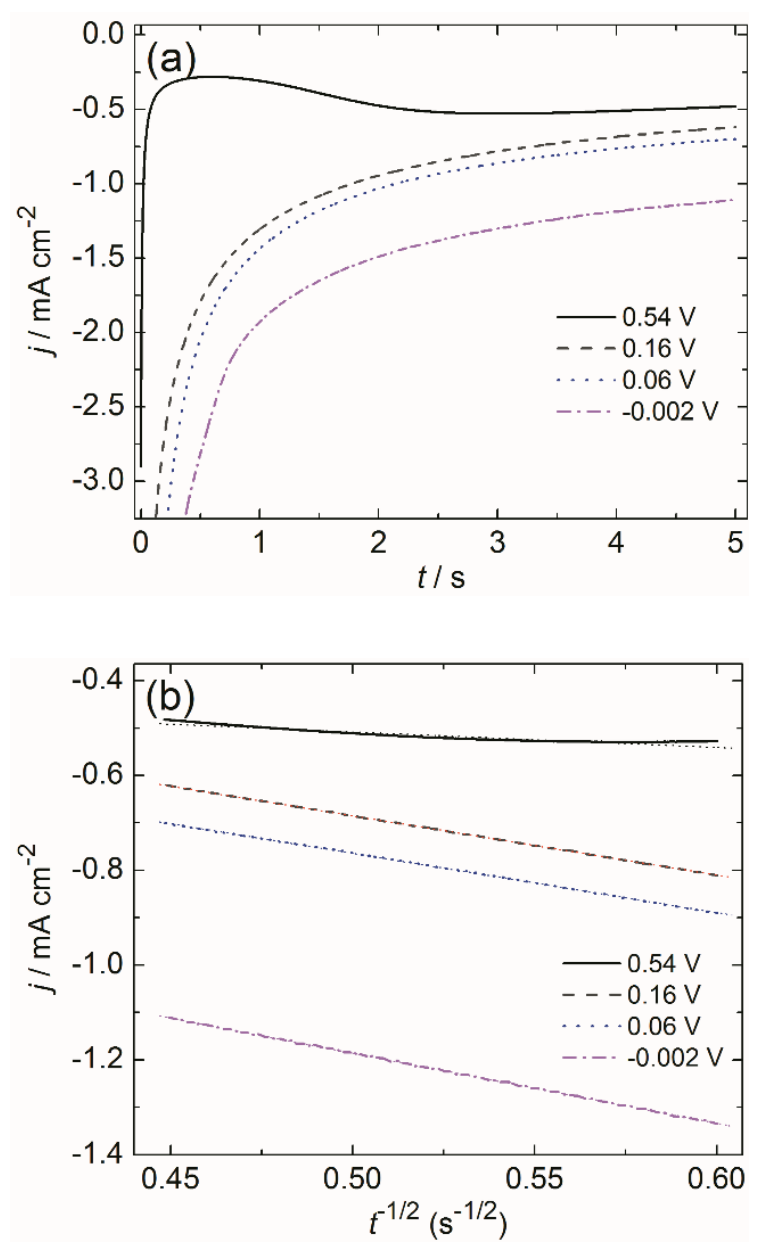

Figure 2. (a) Current-time transient recorded at various overpotentials vs. RHE on a Au substrate in deaerated $0.1 \mathrm{~mol} \mathrm{~L}^{-1} \mathrm{HCl}$ electrolyte containing $0.001 \mathrm{~mol} \mathrm{~L}^{-1} \mathrm{PdCl}_{2}$ (initial/conditioning: $0.79 \mathrm{~V}_{\mathrm{RHE}}, 10 \mathrm{~s}$ ), (b) Plot of current vs. time $^{-1 / 2}$ showing linear characteristic consistent with the Cottrell equation (see supplementary section). The legend shows the corresponding Pd deposition potential at small $0.54 \mathrm{~V}_{\mathrm{RHE}}$ (solid line), medium $0.16 \mathrm{~V}_{\mathrm{RHE}}$ (dash line) and $0.002 \mathrm{~V}_{\mathrm{RHE}}$ (dot line)

\subsection{Characterisation of Pd deposits by cyclic voltammetry in aqueous acidic electrolyte}

Figure 3 shows $\mathrm{CVs}$ of the $\mathrm{Au}$ (111) electrode recorded in $0.1 \mathrm{M}$ $\mathrm{H}_{2} \mathrm{SO}_{4}$ electrolyte at $20 \mathrm{mV} \mathrm{s}{ }^{-1}$ after $\mathrm{Pd}$ was deposited potentiostatically at (a) $0.54 \mathrm{~V}_{\mathrm{RHE}}$ (small overpotential), (b) 0.16 $\mathrm{V}_{\mathrm{RHE}}$ (medium overpotential) and (c) -0.002 $\mathrm{V}_{\text {RHE }}$ (large overpotential) for different deposition times. The CVs for all $\mathrm{Pd}$ electrodes show the characteristic peaks $\left(C_{4}, A_{4}\right)$ for $P d$ oxide reduction $\left(\mathrm{PdO}_{\text {red }}\right)$ /formation $\left(\mathrm{Pd}_{\text {oxi }}\right)$ at around 0.64/0.92 $\mathrm{V}_{\mathrm{RHE}}$ and peaks $\left(C_{1}, C_{2}\right.$ and $\left.A_{1}, A_{2}\right)$ for $H_{\text {UPD }}$ i.e., adsorption $\left(H_{\text {ads }}\right)$, absorption $\left(\mathrm{H}_{\mathrm{abs}}\right)$ and desorption $\left(\mathrm{H}_{\mathrm{des}}\right)$, respectively, in the potential range 0.2-0.06 $V_{\text {RHE. }} A$ pair of peaks $\left(C_{3}, A_{3}\right)$ represents the bulk process of hydrogen absorption/evolution and re-oxidation from the surface of the $\mathrm{Pd}$ at potential $0.01 \mathrm{~V}_{\mathrm{RHE}}$ or more. A pair of broader peaks $\left(\mathrm{C}_{5}, \mathrm{~A}_{5}\right)$ at around $1.16 \mathrm{~V}_{\mathrm{RHE}}$ and 1.4 $\mathrm{V}_{\mathrm{RHE}}$ corresponds to the $\mathrm{Au}$ oxide $\left(\mathrm{Au}_{2} \mathrm{O}_{3}\right)$ reduction and 
formation, respectively, are suppressed when the deposition time was more than $0.2 \mathrm{~s}$. The peak corresponding to the reduction of $\mathrm{Au}_{2} \mathrm{O}_{3}$ was no longer detected as the deposition time increased (insets in Fig. 3) suggesting that the Au surface was fully covered by the $\mathrm{Pd}$ deposits and no $\mathrm{Au}$ surface remained exposed to the electrolyte. The shape of the CVs in the $\mathrm{H}_{\text {UPD }}$ region is similar to those obtained at pseudomorphic $\mathrm{Pd}$ layers deposited on $\mathrm{Au}(111)$ and $\mathrm{Au}(100)$ substrates, ${ }^{[19]}$ which indicate that $\mathrm{Pd}$ was deposited epitaxially. The peak current due to $\mathrm{PdO}_{\text {red }} / \mathrm{Pd}_{\text {oxi }}\left(\mathrm{C}_{4}, \mathrm{~A}_{4}\right), \mathrm{H}_{\text {ads }} / \mathrm{H}_{\text {abs }}$ and $\mathrm{H}_{\text {des }}\left(\mathrm{C}_{1}, \mathrm{C}_{2}\right.$ and $\left.\mathrm{A}_{1}, \mathrm{~A}_{2}\right)$, bulk hydrogen absorption/re-oxidation $\left(\mathrm{C}_{3}, \mathrm{~A}_{3}\right)$ and oxygen evolution (at larger than $1.5 \mathrm{~V}_{\mathrm{RHE}}$ ) from $\mathrm{Pd}$ surfaces increases with increase in the deposition time (see Figure 3 and S4), which indicates that surface roughness of the Pd deposits increases with the deposition time. However, deposition was likely to be low at small overpotential ( $\left.0.54 \mathrm{~V}_{\mathrm{RHE}}\right)$ for longer deposition duration i.e., current for $\mathrm{H}_{\mathrm{ads}} / \mathrm{H}_{\mathrm{abs}}$ and $\mathrm{H}_{\text {des }}$ and $\mathrm{PdO}_{\text {red }}$ increased slightly with increasing the deposition time as shown in Figure S4.
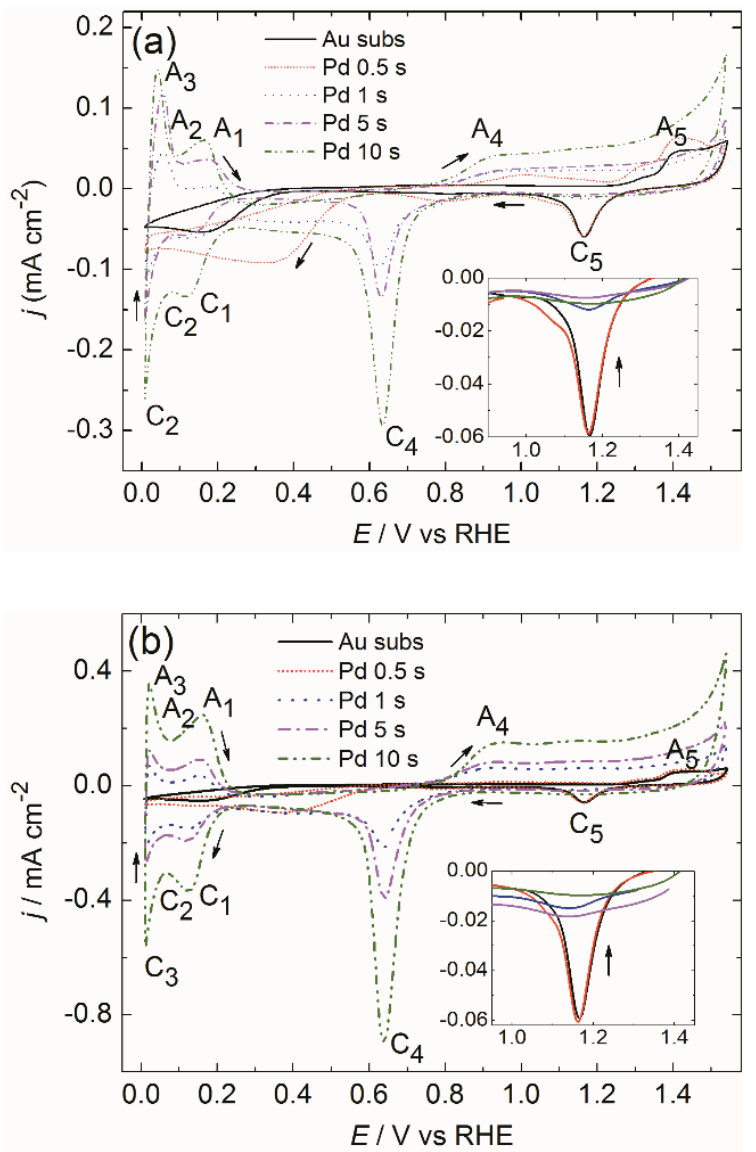

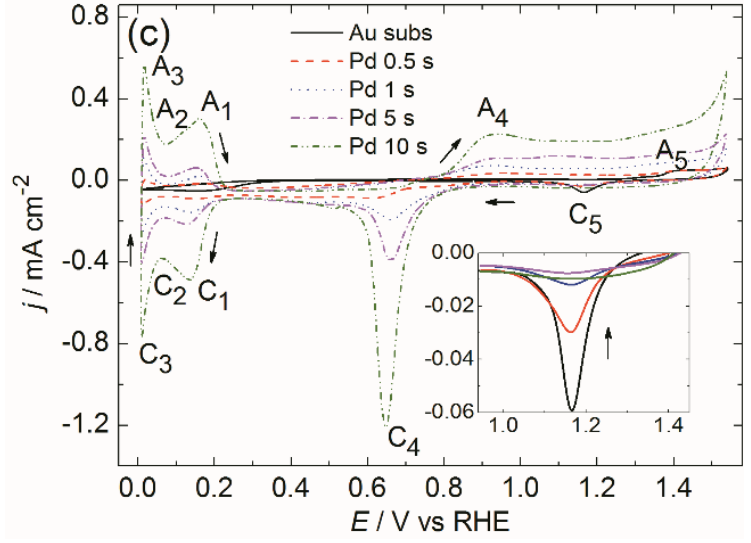

Figure 3. Cyclic voltammetry of the Pd deposited on a Au substrate at (a) 0.54 $\mathrm{V}_{\mathrm{RHE}}$, (b) $0.16 \mathrm{~V}_{\mathrm{RHE}}$ and (d) $-0.002 \mathrm{~V}_{\mathrm{RHE}}$ in deaerated $0.1 \mathrm{M} \mathrm{H}_{2} \mathrm{SO}_{4}$ electrolyte shows $\mathrm{H}_{\text {ads }} / \mathrm{H}_{\text {abs }} / \mathrm{H}_{\text {des }}$ as well as $\mathrm{Pd}$ oxide formation/reduction peaks. $\mathrm{CV}$ s were recorded in static conditions with a scan rate of $20 \mathrm{mV} \mathrm{s}^{-1}$ (initial/conditioning: $0.9 \mathrm{~V}_{\mathrm{RHE}}, 10 \mathrm{~s}$ ) and inset shows the expanded current for the reduction of AuO. The legend indicates the corresponding Pd deposition time.

To examine the nature of the halo-aqua $\mathrm{Pd}^{2+}$ complex, UVvisible spectrophotometric analysis was carried out. The UVvisible absorption spectra (Figure $4 \mathrm{a})$ of the electrolyte $(0.1 \mathrm{~mol}$ $\mathrm{L}^{-1} \mathrm{HCl}$ electrolyte containing $0.01 \mathrm{~mol} \mathrm{~L}^{-1} \mathrm{PdCl}_{2}$ ) are similar to those reported in the literature, which is a spin-forbidden $\mathrm{d}$-d transition $\left({ }^{1} \mathrm{~A}_{2 g} \leftarrow{ }^{1} \mathrm{~A}_{1 g}\right)$ of square-planar $\mathrm{Pd}^{2+}$ complexes in the range between $350-500 \mathrm{~nm} \cdot{ }^{[20]}$ The maximum absorption of the band shifts to shorter wavelengths when the $\mathrm{Cl}^{-}$ligands are exchanged for $\mathrm{H}_{2} \mathrm{O}$ ligands on going from a highly acidic to a lower acidic electrolyte, which is in agreement with the spectrochemical series of the ligands. ${ }^{[20]}$ The maximum absorption peak of the band at $432 \mathrm{~nm}$ is given by the coordinated complex $\left[\mathrm{PdCl}_{3}\right]\left[\mathrm{H}_{2} \mathrm{O}\right]^{-}$, in which $\mathrm{Cl}^{-}$ligands exchanged for $\mathrm{H}_{2} \mathrm{O}$ ligands of the complex $[\mathrm{PdCl} 4]^{2-}$ (assigned absorption peak at $467 \mathrm{~nm}$ ) and the complex is stabilised by charge transfer from ligands to the central $\mathrm{Pd}^{2+}$ ions. ${ }^{[20-21]}$ On further hydrolysis of $\left.\mathrm{PdCl}_{3}\right]\left[\mathrm{H}_{2} \mathrm{O}\right]^{-}$towards a near neutral electrolyte, more $\mathrm{Cl}^{-}$ligands are displaced by $\mathrm{H}_{2} \mathrm{O}$ to produce complexes such as $\left[\mathrm{PdCl}_{4-x}\right]\left[\mathrm{H}_{2} \mathrm{O}\right]_{x}^{(x-2)}(\mathrm{x}=0-4)$ [20] ${ }^{[20}$ These complexes show a larger shift of the $\mathrm{Pd}^{2+} \mathrm{d}-\mathrm{d}$ transition band to shorter wavelengths $(420 \mathrm{~nm})$ and a change in colour of the electrolyte to brown as shown in the inset of Figure $4 \mathrm{a}$. After 10 times dilution to $0.001 \mathrm{~mol} \mathrm{~L}^{-1} \mathrm{PdCl}_{2}$, the maximum absorption peak of the band did not show a wavelength shift (Figure 4b), which confirmed that concentration of the active ions in the electrolyte doesn't affect the coordination nature of the complexes. 

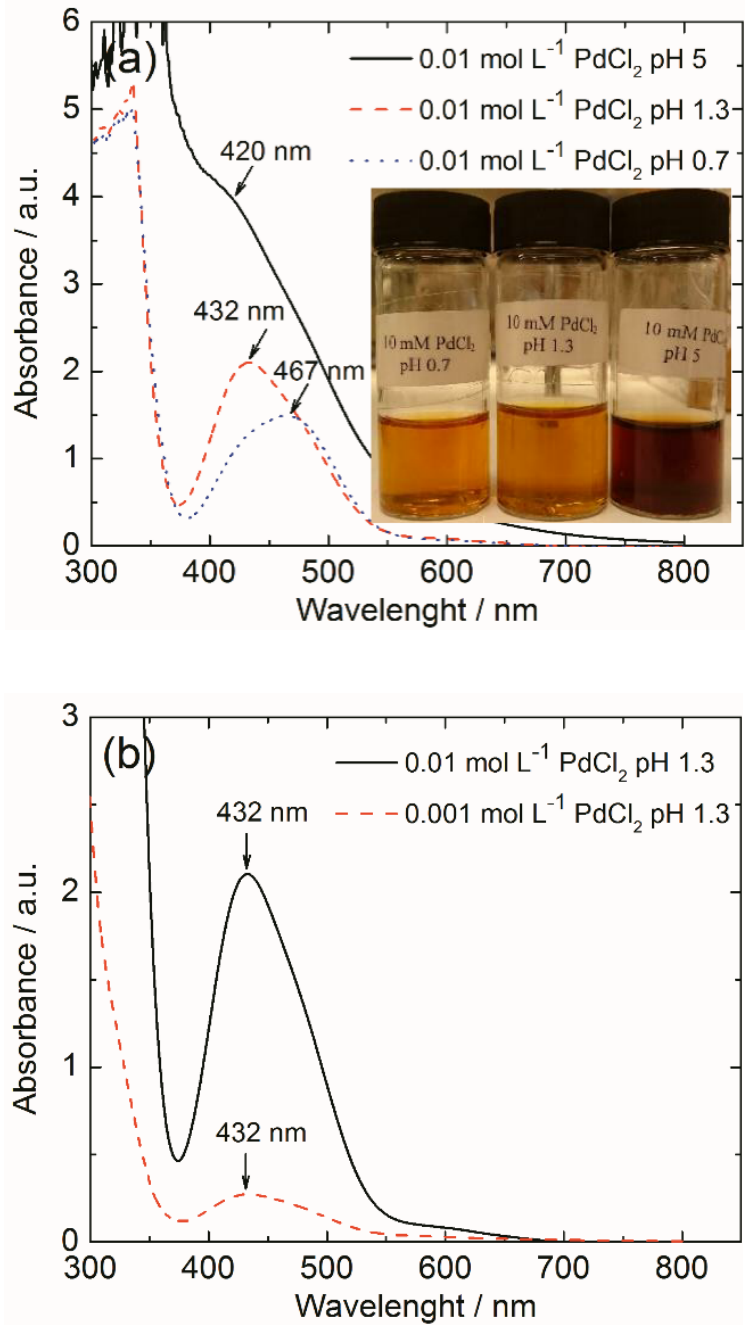

Figure 4. UV-visible absorption spectra of $0.1 \mathrm{~mol} \mathrm{~L}^{-1} \mathrm{HCl}$ electrolyte containing (a) $0.01 \mathrm{~mol} \mathrm{~L}^{-1} \mathrm{PdCl}_{2}$ at $\mathrm{pH}$ 0.7, 1.3 and 5; (b) comparison between 0.001 and $0.01 \mathrm{~mol} \mathrm{~L}^{-1}$ concentration of $\mathrm{Pd}^{2+}$ ions at $\mathrm{pH}$ 1.3. Inset: Colour changes of $0.1 \mathrm{~mol} \mathrm{~L}^{-1} \mathrm{HCl}$ containing $0.01 \mathrm{~mol} \mathrm{~L}^{-1} \mathrm{PdCl}_{2}$ with increase $\mathrm{pH}$.

\subsection{Growth mode and structural characterisation of Pd NPs}

Following the deposition of $\mathrm{Pd}$ from the aforementioned electrolyte by the potentiostatic pulse at various overpotentials, Pd NPs were observed in an ex-situ examination of the electrode surface using a high resolution FEG-SEM. Figure 5 shows ex-situ FEG-SEM of the different sizes of Pd NPs grown on Au surface where the deposition charge was controlled to $\left.433 \mu \mathrm{C} \mathrm{cm}{ }^{-2}(1 \text { monolayer } \mathrm{Pd}=440 \mu \mathrm{C} \mathrm{cm})^{-2}\right)^{[22]}$ for each potential. The nanoparticles are grown by direct electrochemical reduction of $\left[\mathrm{PdCl}_{4}\right]^{2-}$ ions from the electrolyte on the Au surface according to equation 1 . The nanoparticles are randomly dispersed and spherical in shape, in which a large fraction of the substrate is unoccupied. The unoccupied space accounts for the planar diffusion controlled growth of the nuclei as the deposition progresses. The mean particle diameter and distribution were determined by measuring the sizes of at least
1500 particles. The mean diameter of particles deposited at small, medium and large overpotential are $3.8 \mathrm{~nm}(\sigma=1.8), 2.8$ $\mathrm{nm}(\sigma=1.2)$, and $3.2 \mathrm{~nm}(\sigma=1.7)$, respectively. The average particles size were determined as described in the experimental section 2.3 (also, see the related description in Figure 6 and S5 for more details). It is observed from those measurement that particle sizes vary slightly at each overpotential i.e., dependent on the applied overpotential. The obtained result implies that the average cluster size becomes smaller with higher overpotential for the same deposition time i.e., higher density of nuclei at higher overpotential leads to a smaller average size.
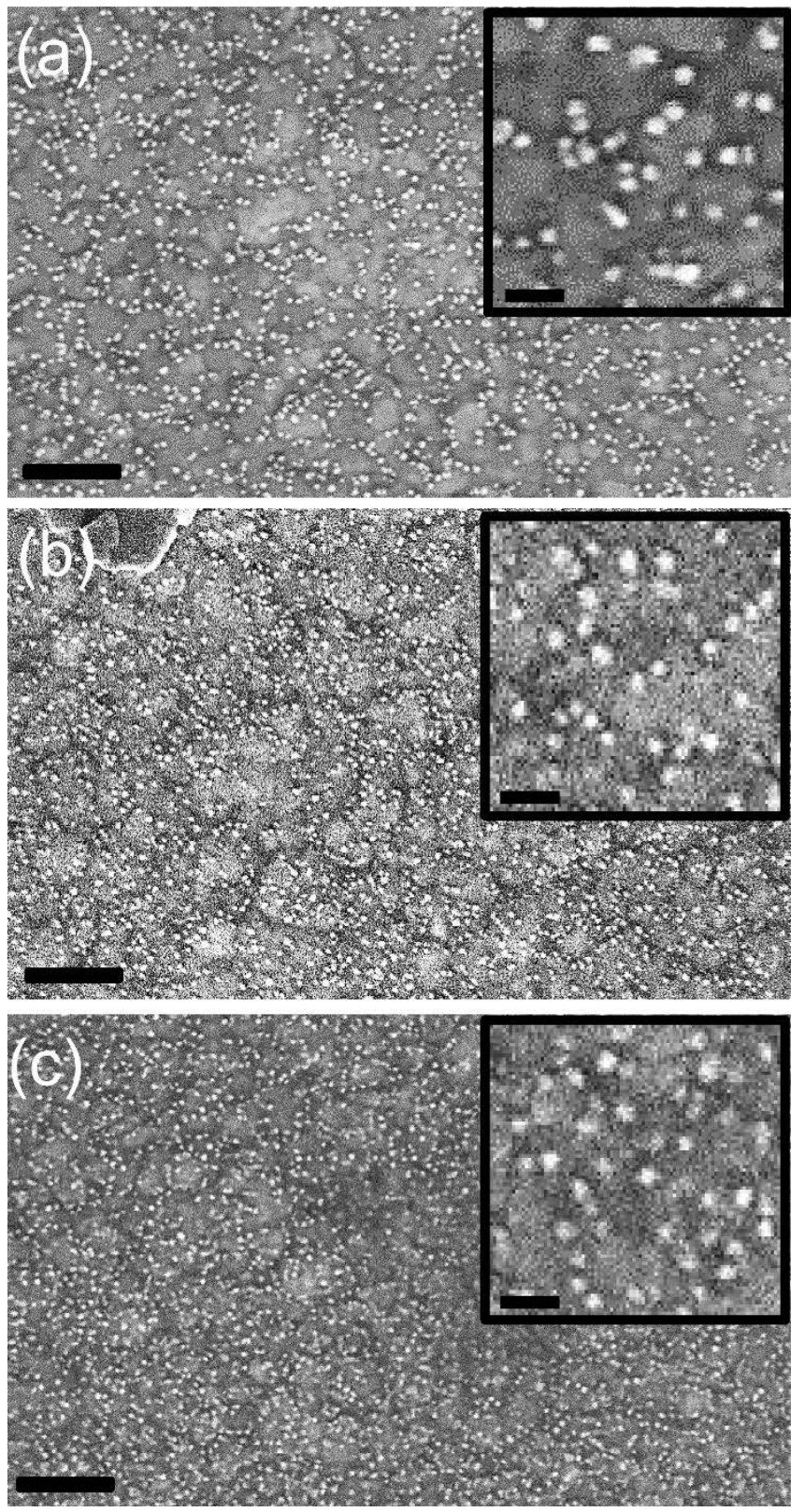

Figure 5. Ex-situ FEG-SEM images for Pd nucleation and growth on a Au substrate electrodeposited potentiostatically at (a) $0.54 \mathrm{~V}_{\mathrm{RHE}}$, (b) $0.16 \mathrm{~V}_{\mathrm{RHE}}$ and

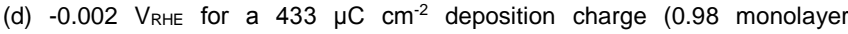


equivalent). Inset corresponds to a high magnification FEG-SEM image. Scale bars in the big panel and in the inset are $100 \mathrm{~nm}$ and $20 \mathrm{~nm}$, respectively. The electrolyte was made up with deaerated $0.1 \mathrm{~mol} \mathrm{~L}^{-1} \mathrm{HCl}$ electrolyte containing $0.001 \mathrm{~mol} \mathrm{~L}^{-1} \mathrm{PdCl}_{2}$.

The growth of Pd NPs was further examined by increasing the amount of $\mathrm{Pd}$ deposition charge. A higher amount of $\mathrm{Pd}$

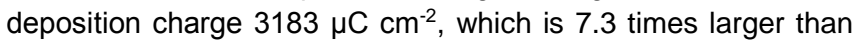
that of Fig.5, was controlled potentiostatically on each electrode and representative FEG-SEM images are shown in Figure 6. Pd NPs gradually cover the whole Au surface with a high degree of monodispersity as the deposition progressed. There seems to be a general tendency to increase in size and broaden the size distribution of the nanoparticles as the deposition continues based on the inset profile in Figure 6. According to the FEGSEM images discussed above firstly, nuclei and clusters of nuclei are formed randomly on the Au surface; secondly, new clusters are also formed all over the surface as the deposition proceeded; and thirdly, stable clusters are grown by the direct reduction of $\left[\mathrm{PdCl}_{4}\right]^{2-}$ ions towards a full coverage of the substrate as the deposition continued. A schematic model for the electrochemical nucleation and growth of $\mathrm{Pd}$ deposition at small, medium and large overpotential based on the FEG-SEM results discussed above is shown in Figure 7 . The monodispersed Pd nanoparticle are formed without and with a little or large interaction of $\mathrm{H}_{\text {UPD }}$ on the growing nuclei of $\mathrm{Pd}$ and seemingly, $\mathrm{H}_{\text {UPD }}$ didn't obstruct the growth of the deposits.
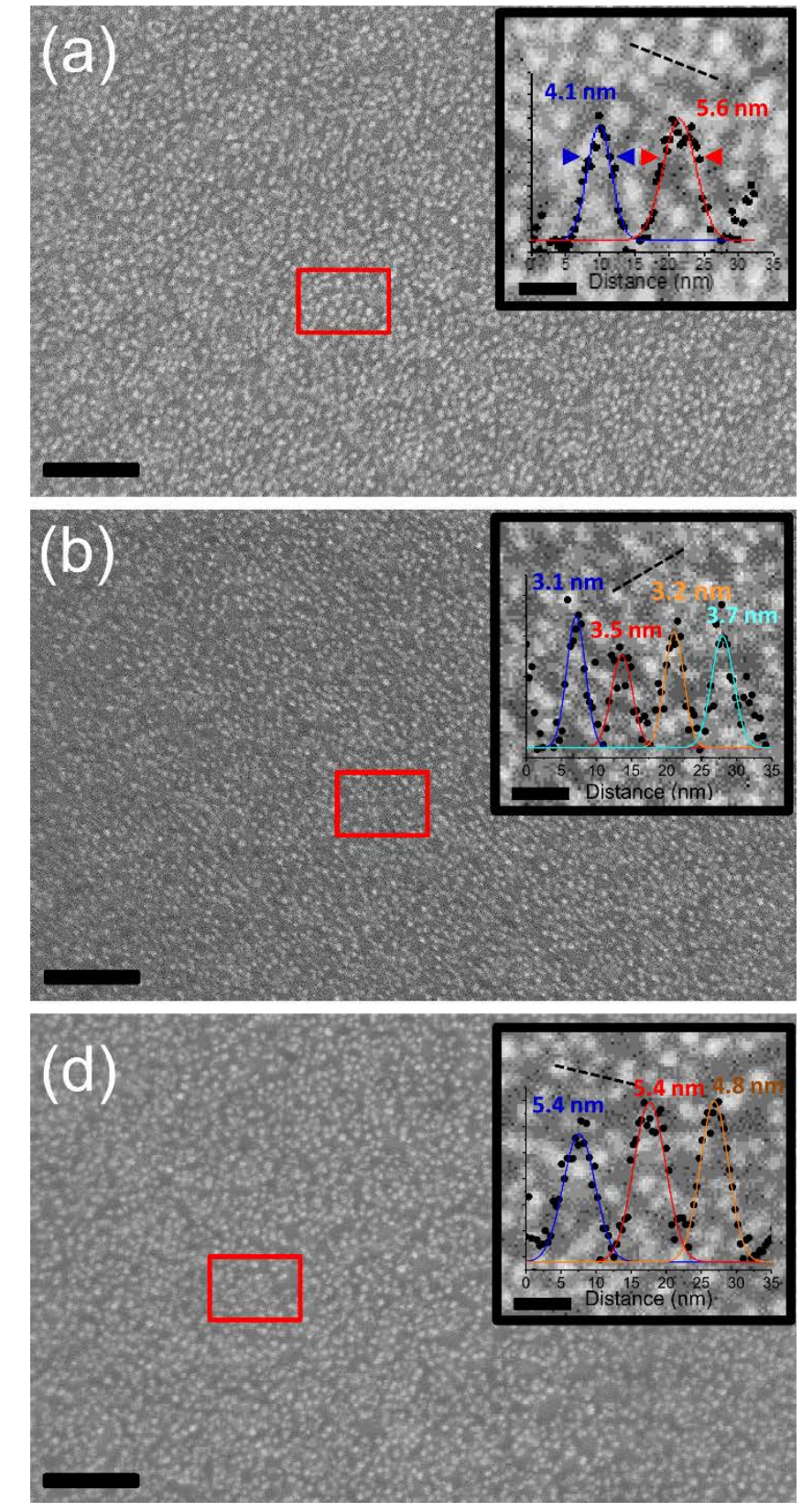

Figure 6. Ex-situ FEG-SEM images of the Pd NPS on a $\mathrm{Au}$ substrate electrodeposited potentiostatically at (a) $0.54 \mathrm{~V}_{\mathrm{RHE}}$, (b) $0.16 \mathrm{~V}_{\mathrm{RHE}}$ and (d) $0.002 V_{\text {RHE }}$ for a $3183 \mu \mathrm{C} \mathrm{cm}^{-2}$ deposition charge. The electrolyte was made up with deaerated $0.1 \mathrm{~mol} \mathrm{~L}^{-1} \mathrm{HCl}$ electrolyte containing $0.001 \mathrm{~mol} \mathrm{~L}^{-1} \mathrm{PdCl}_{2}$. Insets show the higher magnification images of the areas within the red rectangles, in which examples of profile plots are shown. Dashed black lines represent the cuts where the profiles were analysed. To illustrate the variation in particle sizes, Gaussian fits were performed, the FWHM values of which are noted next to the profiles. Scale bars in the big panel and in the inset are 100 $\mathrm{nm}$ and $20 \mathrm{~nm}$, respectively. 


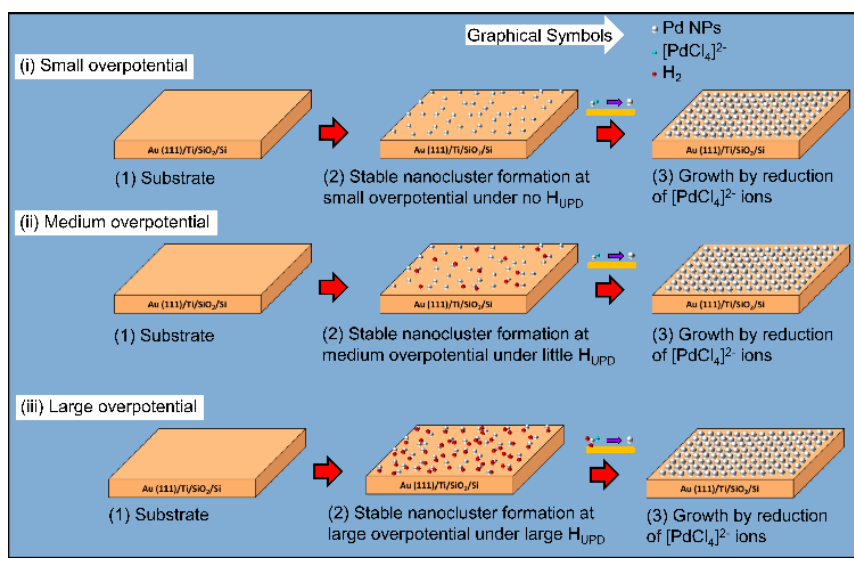

Figure 7. Schematic illustration of the electrochemical growth mechanism of the Pd deposition on a Au substrate when the overpotential is (i) small with no interaction of HUPD, (ii) medium with a little interaction of HUPD, and (iii) large with a significant interaction of $\mathrm{H}_{U P D}$, on the growing nuclei.

The elemental composition, chemical and electronic states of Pd NPs at the Au (111) interface were investigated by XPS as shown in Figure 8a for a deposition charge of $3183 \mu \mathrm{C} \mathrm{cm}^{-2}$, similar to the deposition charge for which FEG-SEM is shown in Figure 6. Survey scans were carried out initially on a contaminant free Au (111) surface. The survey showed that all the samples contain $\mathrm{O}, \mathrm{C}$ and $\mathrm{Pd}$ photoelectron peak consistent with the modification of the Au surface with Pd NPs. Pd NPs on the gold surface were prepared by applying various potentials while maintaining the same deposition charge. Hence, Au substrate modified with $\mathrm{Pd}$ nanoparticles has spin orbit doublets with $\mathrm{Pd} 3 \mathrm{~d}_{5 / 2}$ and $\mathrm{Pd} 3 \mathrm{~d}_{3 / 2}$ peaks at $335.8 \mathrm{eV}$ and $341.3 \mathrm{eV}$, respectively. The latter observation seems to be the same for all the electrodes regardless of the applied potential during $\mathrm{Pd}$ deposition. That means that there was not any binding energy shift, a fact which indicates that the deposited metallic Pd NPs are pure or contaminant-free. To investigate the crystal structure of Pd NPs, XRD measurements were performed as shown in Figure $8 \mathrm{~b}$. A strong diffraction peak was observed, which can be assigned to the (111) face-centred cubic (fcc) structure of metallic Pd along with a tiny peak for the (200) facet.

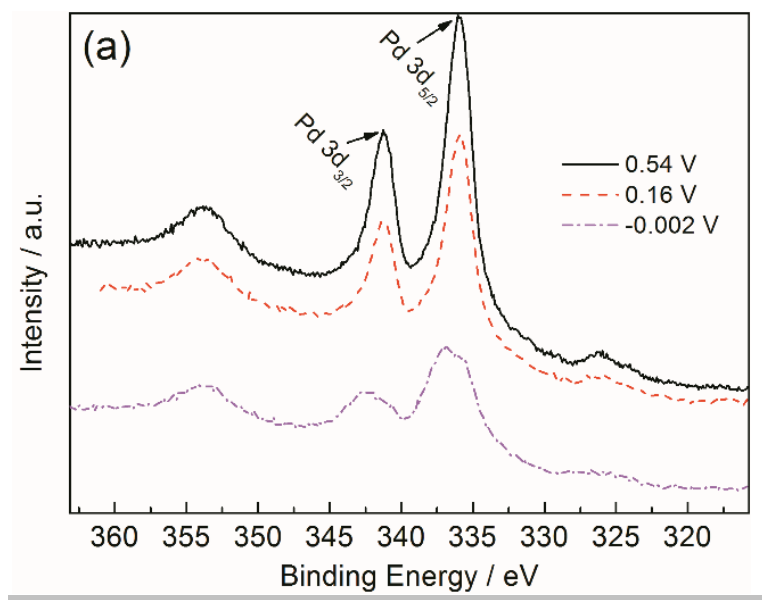

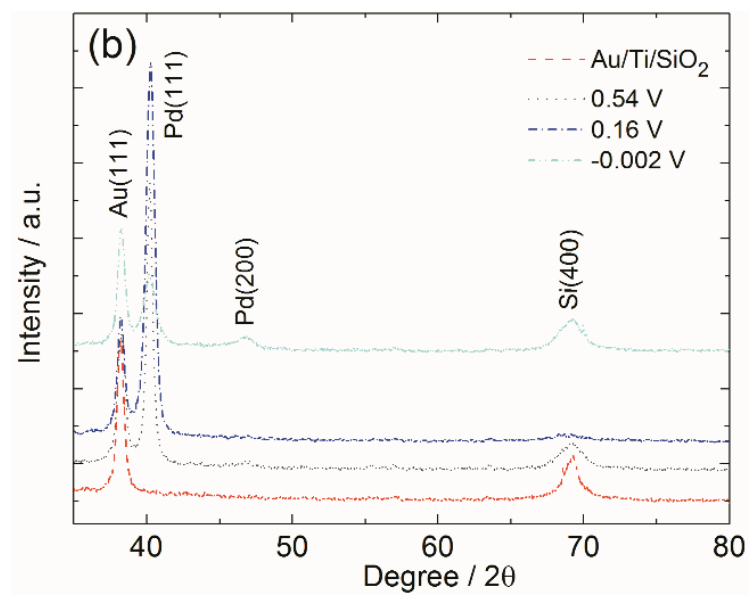

Figure 8. (a) XPS and (b) XRD of Pd NPs on a Au substrate for a total deposition charge of $3183 \mu \mathrm{C} \mathrm{cm}^{-2}$. The legend shows the corresponding $\mathrm{Pd}$ deposition potential at small $0.54 \mathrm{~V}_{\mathrm{RHE}}$, medium $0.16 \mathrm{~V}_{\mathrm{RHE}}$ and $-0.002 \mathrm{~V}_{\mathrm{RHE}}$.

\subsection{Electrocatalytic performance measurement of Pd NPs}

CVs for the Pd NPs based electrode (corresponding ex-situ FEG-SEM images were shown in Figure 5 and 6) were recorded for the ferrocyanide $\left(\left[\mathrm{Fe}(\mathrm{CN})_{6}\right]^{4-}\right) /$ ferricyanide $\left(\left[\left(\mathrm{Fe}(\mathrm{CN})_{6}\right]^{3-}\right)\right.$ system, which demonstrate a quasi-reversible one-electron redox behaviour at the Pd NPs as shown in Figure 9. Before examining the redox behaviour in the above electrolyte, the deposited Pd NPs were electrochemically cleaned in $0.5 \mathrm{~mol} \mathrm{~L}^{-1}$ $\mathrm{KOH}$ electrolyte by $\mathrm{CV}$ technique. Because it is a surfactant-free Pd NPs surface (as confirmed by XPS in Figure 8a), steadystate CVs were achieved after a few cycles. The redox current of $\mathrm{Pd}$ NPs deposited at medium (0.16 $\left.\mathrm{V}_{\mathrm{RHE}}\right)$ and large $(-0.002$ $V_{\mathrm{RHE}}$ ) overpotential as shown in Figure $9 \mathrm{a}$, is similar to that of the Au substrate $\left(I_{\mathrm{pa}}=0.67 \mathrm{~mA} \mathrm{~cm}{ }^{-2}\right.$ and $\left.I_{\mathrm{pc}}=0.76 \mathrm{~mA} \mathrm{~cm}^{-2}\right)$ with an anodic $\left(E_{p a}\right)$-cathodic $\left(E_{p c}\right)$ peak potential separation $\left(\Delta E_{p}=\right.$ $\left.E_{p a}-E_{p c}\right)$ of $0.09 \mathrm{~V}$, which indicates faster electron transfer kinetics. However, peak separation of Pd NPs deposited at small (0.54 $\left.\mathrm{V}_{\mathrm{RHE}}\right)$ increased to $0.13 \mathrm{~V}$ with a slight decrease in the corresponding redox current $\left(\mathrm{I}_{\mathrm{pa}}=0.56 \mathrm{~mA} \mathrm{~cm} \mathrm{~cm}^{-2}\right.$ and $\mathrm{I}_{\mathrm{pc}}=0.62$ $\mathrm{mA} \mathrm{cm} \mathrm{cm}^{-2}$ ). This behaviour is due to the partial hindrance of $\left(\left[\mathrm{Fe}(\mathrm{CN})_{6}\right]^{4-}\right) / \quad\left(\left[\left(\mathrm{Fe}(\mathrm{CN})_{6}\right]^{3-}\right)\right.$ redox reaction on the $\mathrm{Pd} \mathrm{NPs}$ surface and slower electron transfer kinetics that leads to a lower current and higher peak separation. However, Pd NPs deposited at small overpotential, whose particles size are quite large by comparison with those deposited at medium and large overpotential might have less activated surface area for redox reaction. As the deposition proceeds, nanoparticles or clusters grew further through the fresh reduction of ions into nanoparticles of the homogenous active sites and surface area. As can be seen from the Figure 9b, the redox peak potentials of the ferrocyanide/ferricyanide system are similar for all Pd NPs electrodes irrespective of the overpotential applied when deposited for longer period of time (corresponding FEG-SEM image is shown in Figure 6). The anodic and cathodic peak potential for all Pd NPs are observed at $0.95 \mathrm{~V}_{\mathrm{RHE}}$ and $0.86 \mathrm{~V}_{\mathrm{RHE}}$, respectively, and the corresponding anodic-cathodic peak 
potential separation $\left(\Delta \mathrm{E}_{\mathrm{p}}=\mathrm{E}_{\mathrm{pa}}-\mathrm{E}_{\mathrm{pc}}\right)$ is $0.09 \mathrm{~V}$. The obtained $\Delta \mathrm{E}_{\mathrm{p}}$ value for Pd NPs is similar with the value of the Au substrate $\left(\Delta \mathrm{E}_{\mathrm{p}}=0.09 \mathrm{~V}\right)$, but it should be borne in mind that the $\mathrm{Au}$ particles were deposited under vacuum by a sputtering technique, which affords high purity blanket deposits but is more expensive by comparison with the electrodeposition method. A small $\Delta \mathrm{E}_{\mathrm{p}}$ value obtained for $\mathrm{Pd}$ NPs indicates that a good reversibility and electrochemical activity are maintained on the Pd nanoparticles surface. ${ }^{[18 a]}$ The redox current of Pd NPs varies slightly with each overpotential applied for their deposition, which are $I_{\mathrm{pa}}=0.80 \mathrm{~mA} \mathrm{~cm}{ }^{-2}$ and $I_{\mathrm{pc}}=0.85 \mathrm{~mA} \mathrm{~cm}^{-2}$ (small overpotential), $\mathrm{I}_{\mathrm{pa}}=0.75 \mathrm{~mA} \mathrm{~cm}{ }^{-2}$ and $\mathrm{I}_{\mathrm{pc}}=0.80 \mathrm{~mA} \mathrm{~cm}$ (medium overpotential), and $\mathrm{I}_{\mathrm{pa}}=0.77 \mathrm{~mA} \mathrm{~cm}^{-2}$ and $\mathrm{I}_{\mathrm{pc}}=0.85$ $\mathrm{mA} \mathrm{cm}-2$ (large overpotential). The ratio of the cathodic to anodic current is close to 1 , suggesting that the reaction undergoes a quasi-reversible redox process. The redox currents for $\mathrm{Pd}$ nanoparticles are 1.1 to 1.2 times higher than that of the $\mathrm{Au}$ substrates i.e., a larger electrochemically activated surface area of the electrodeposited Pd NPs and faster electron transfer kinetics by comparison with the sputtered Au. The redox current for Pd NPs complied with the theoretically calculated value $\left(0.825 \mathrm{~mA} \mathrm{~cm}^{-2}\right)$ from Randles-Sevcik equation, in which a lower value for the Au substrate can be interpreted in terms of the lower activated surface area for the redox reaction.
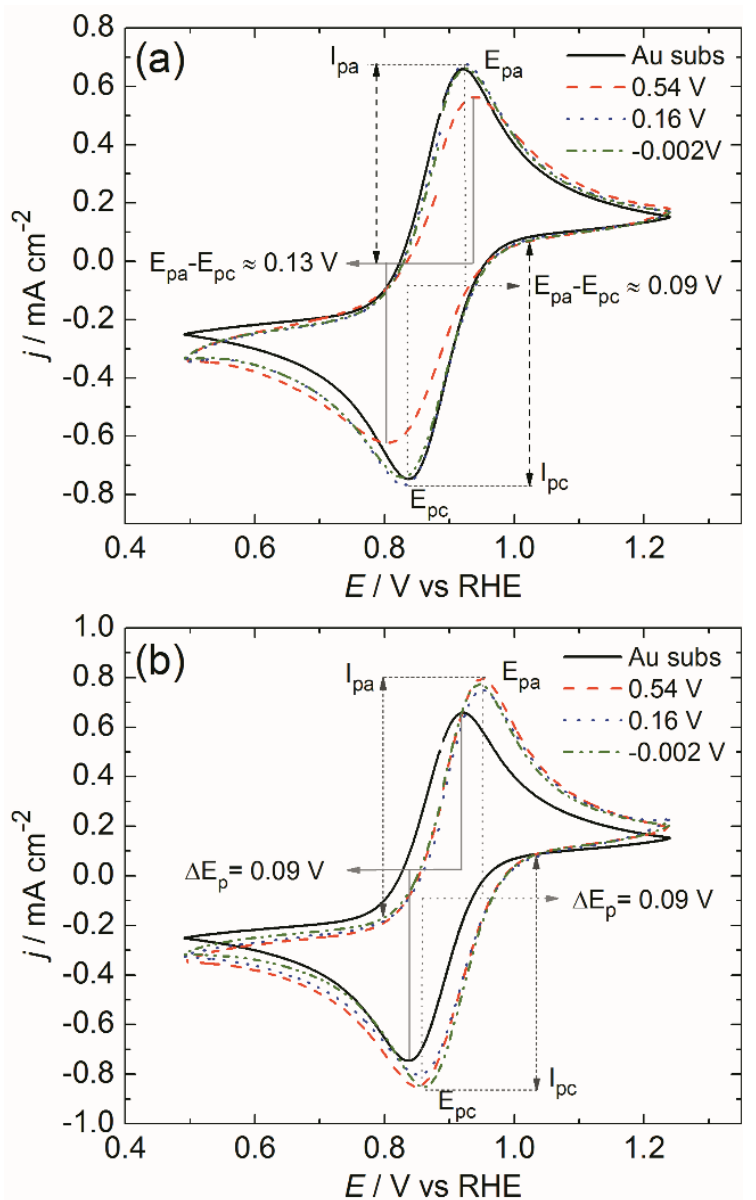

Figure 9. Cyclic voltammetry of Pd NPs on a Au substrate (a) $433 \mu \mathrm{C} \mathrm{cm}^{-2}$ (corresponded SEM is shown Figure 4) and (b) $3183 \mu \mathrm{C} \mathrm{cm}^{-2}$ (corresponded $\mathrm{SEM}$ is shown in Figure 5 ) recorded in deaerated $0.005 \mathrm{~mol} \mathrm{~L}^{-1} \mathrm{~K}_{3}[\mathrm{FeCN}]_{6}$ and $1 \mathrm{~mol} \mathrm{~L}^{-1} \mathrm{KCl}$ electrolyte. CVs were recorded in static conditions with a scan rate of $50 \mathrm{mV} \mathrm{s}^{-1}$ (initial/conditioning: $0.9 \mathrm{~V}_{\mathrm{RHE}}, 10 \mathrm{~s}$ ).

Pd NPs were characterised by $\mathrm{CV}$ in deaerated $0.5 \mathrm{~mol} \mathrm{~L}^{-1}$ $\mathrm{KOH}$ aqueous electrolyte as shown in Figure 10. These CVs show similar characteristic features to those reported in the literature for hydrogen adsorption $\left(C_{2}, C_{3}\right)$ and desorption $\left(A_{2}\right.$, $\left.A_{3}\right)$, oxide formation $\left(A_{1}\right)$ and reduction $\left(C_{1}\right){ }^{[23]}$ The pre-peak $\left(A_{1}^{\prime}\right)$ and $\left(C_{1}^{\prime}\right)$ are associated with the oxidation and reduction of the $\mathrm{Pd}$ NPs surface, respectively, before the main process occurs. The electroactive surface area (EASA) was calculated from $\mathrm{Pd}$ oxide reduction ( $\left.\mathrm{PdO}_{\mathrm{red}}\right)$ peak at $0.63 \mathrm{~V}_{\mathrm{RHE}}$ after subtraction of the charge for a double layer charging capacitance. A conversion factor of $424 \mu \mathrm{C} \mathrm{cm}$-2 was used corresponding to the removal of a full monolayer of $\mathrm{Pd}$ oxide. The specific surface area (SSA) of the Pd NPs in $\mathrm{m}^{2} / \mathrm{g}$ was defined as the EASA of the Pd NPs $\left(\mathrm{cm}^{2} / \mathrm{cm}^{2}\right.$ Au substrate) divided by the amount $\mathrm{Pd}$ loading. These data are summarised in Table 1 along with the electrocatalytic activity for ethanol electrooxidation in aqueous alkaline electrolytes.

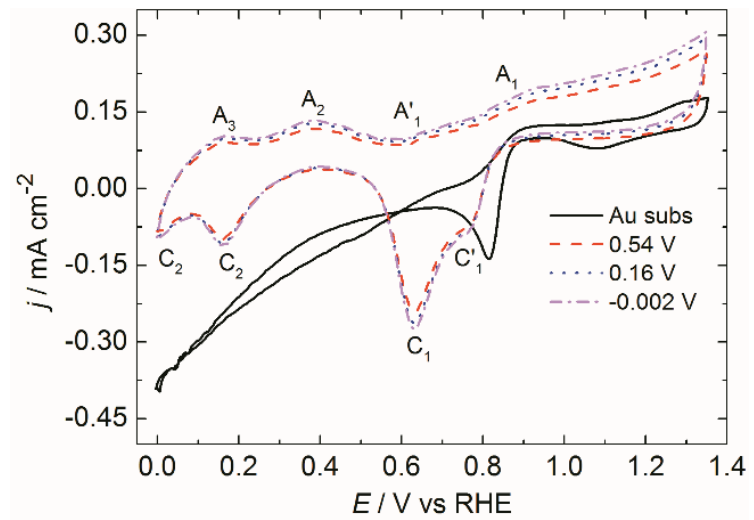

Figure 10. Cyclic voltammetry of Pd NPs deposited on a Au substrate recorded in deaerated $0.5 \mathrm{~mol} \mathrm{~L}^{-1} \mathrm{KOH}$ aqueous electrolyte. CVs were recorded in static conditions with a scan rate of $20 \mathrm{mV} \mathrm{s}^{-1}$ (initial/conditioning: $1.0 \mathrm{~V}_{\mathrm{RHE}}, 10 \mathrm{~s}$ ). Each electrode contains a total Pd deposition charge of 3183 $\mu \mathrm{C} \mathrm{cm}-2$ (i.e., $1.75 \times 10^{-6} \mathrm{~g} \mathrm{~cm}^{-2}$ ). 
Table 1. Overpotential dependent electroactive surface area (EASA), specific surface area (SSA), ethanol electrooxidation and mass activity of Pd NPs at 293K. The specific activity was normalised to the EASA of Pd. The activities were measured at the forward peak potential and geometrical surface area of the Au substrate was $0.6 \mathrm{~cm}^{2}$.

\begin{tabular}{|c|c|c|c|c|c|c|c|c|}
\hline $\begin{array}{l}\mathrm{V}_{\mathrm{RHE}} \text { for Pd NPs } \\
\text { deposition }\end{array}$ & $\begin{array}{l}\text { Pd loading } \mathrm{g} \\
\mathrm{cm}^{-2} \times 10^{-6}\end{array}$ & $\begin{array}{l}\text { EASA } \\
\mathrm{cm}^{2}(\mathrm{Pd}) \mathrm{cm}^{-2} \text { (subs) }\end{array}$ & SSA $m^{2} g^{-1}(P d)$ & $\begin{array}{l}\text { Ethanol } \\
\text { current } \\
\mathrm{mA} \mathrm{cm}^{-2} \text { (subs) }\end{array}$ & $\begin{array}{l}\text { electrooxidation } \\
\text { specific activity } \\
\text { mA cm}{ }^{-2}(P d)\end{array}$ & $\begin{array}{l}\text { Mass } \\
\mathrm{mA} \\
10^{6}\end{array}$ & $\begin{array}{r}\text { activity } \\
\mathrm{g}^{-1}(\mathrm{Pd}) \quad \mathrm{x}\end{array}$ & $I_{f} / I_{b}$ \\
\hline 0.54 & 1.73 & 1.58 & 91.32 & 17.33 & 10.96 & & 10.02 & 0.86 \\
\hline 0.16 & 1.67 & 1.62 & 97.00 & 18.70 & 11.54 & & 11.20 & 0.95 \\
\hline-0.002 & 1.64 & 1.64 & 100.00 & 19.79 & 12.07 & & 12.07 & 1.05 \\
\hline
\end{tabular}

The specific surface area (SSA) of Pd NPs deposited at all overpotentials at a nearly similar mass loading varies only slightly for each deposit. However, this difference can be attributed to the particle size and counts of the smallest particles as shown in particles density character (Figure S6). The lowest SSA value $\left(91.32 \mathrm{~m}^{2} \mathrm{~g}^{-1}\right)$ for Pd NPs deposited at $0.54 \mathrm{~V}_{\mathrm{RHE}}$ is due to comparatively larger particle size (i.e., 5-8 nm with maximum counts for $5.5 \mathrm{~nm} \mathrm{NPs}$ ) effect while the highest values $97.00 \mathrm{~m}^{2} \mathrm{~g}^{-1}$ and $100.00 \mathrm{~m}^{2} \mathrm{~g}^{-1}$ for the Pd NPs deposited at 0.16 $V_{\text {RHE }}$ and $-0.002 V_{\text {RHE, }}$ respectively, is due to the combined effects of smaller particles size $(2-8 \mathrm{~nm})$ with the maximum counts for only $5 \mathrm{~nm}$ Pd NPs. The SSA values of our electrochemically deposited Pd NPs are remarkably higher than the values for electrodeposited nonporous $\mathrm{Pd}\left(60 \mathrm{~m}^{2} \mathrm{~g}^{-1}\right),{ }^{[24]} \mathrm{Pd}$ coated CNT $\left(25.8 \mathrm{~m}^{2} \mathrm{~g}^{-1}\right),{ }^{[25]}$, Pd nanowires synthesised by electron beam irradiation of a precursor mixture $\left(12 \mathrm{~m}^{2} \mathrm{~g}^{-1}\right)^{[26]}$ and $\mathrm{Pd}$ black (17-23 $\left.\mathrm{m}^{2} \mathrm{~g}^{-1}\right) \cdot{ }^{[27]}$ However, of note is the deposition charge of $\mathrm{Pd}$ at $-0.002 \mathrm{~V}_{\mathrm{RHE}}$ may include small amount of HUPD charge which is in the range of HUPD and thus, measured SSA value for Pd NPs is an indicative, which was expected to be higher if $\mathrm{H}_{\text {UPD }}$ charges were subtracted. On the other hand, small and medium overpotential both are positive of $\mathrm{H}_{\text {UPD }}$ and thus, calculated SSA values for Pd NPs deposited at those overpotential are accurate.

The electrocatalytic performance of $\mathrm{Pd}$ NPs as anode catalysts for alkaline direct alcohol fuel cells (ADAFCs) was evaluated by electrooxidation of ethanol, one of the highest energy density and largely scalable production fuels from the fermentation of biomass. Typical CVs for electrooxidation of ethanol on Pd NPs and the Au substrate electrode in alkaline electrolyte are shown in Figure 11a. Ethanol electrooxidation exhibited two well-defined current peaks, the first at $0.8 V_{\text {RHE }}$ on the forward scan under anodic conditions and the second at $0.68 V_{R H E}$ on the reverse scan under cathodic conditions. It is clearly seen that the forward and reverse peaks for all Pd NPS electrode are sharper with a higher electrooxidation current by comparison with the substrate Au electrode. The peak on the forward scan is attributed to the electrooxidation of the freshly chemisorbed ethanol species on the Pd NPs and the peak on the reverse scan is caused by the oxidation of the incompletely oxidised carbonaceous species e.g., $\left(\mathrm{CH}_{3} \mathrm{CO}\right)_{\text {ads, }}$, formed during the dissociative adsorption of ethanol on the Pd during the forward scan. ${ }^{[28,29]}$ The formation of the oxide layer can block the adsorption of the new reactive species on the Pd surface and eventually lead to the decrease in the electrocatalytic activity. As the anodic scan continues more Pd oxide covers the surface of the Pd NPs and therefore, the current for the electrooxidation of ethanol is decreased at $0.9 \mathrm{~V}_{\mathrm{RHE}}$ and no current flows thereafter as the scan is continued. The electrode reactivates again in the reverse scan once the oxide is removed from the Pd NPs surface giving a second oxidation peak at $0.68 \mathrm{~V}_{\mathrm{RHE} .}{ }^{[29-30]}$ The forward scan onset potential refers to the overpotential required for the electrooxidation of ethanol and it is seen that current started to flow for all Pd NPs electrodes at an overpotential ca. $0.32 V_{\text {RHE }}$, which is about $0.33 \mathrm{~V}$ more negative than the $\mathrm{Au}$ substrate $\left(0.65 \mathrm{~V}_{\mathrm{RHE}}\right)$. This fact indicates that the stripping reaction of the dissociative adsorbed intermediates $\left(\mathrm{H}_{3} \mathrm{CO}\right)_{\text {ads }}$ of ethanol on the Pd NPs commences at a more negative potential than that of $\mathrm{Au}$. The stripping reaction is known to be the rate determining step for the electrooxidation of ethanol on $\mathrm{Pd}$ electrocatalyst in alkaline electrolyte as reported in our previous work. ${ }^{[29]}$ Therefore, electrooxidation of ethanol in alkaline electrolyte is kinetically more favourable on Pd NPs than on Au.

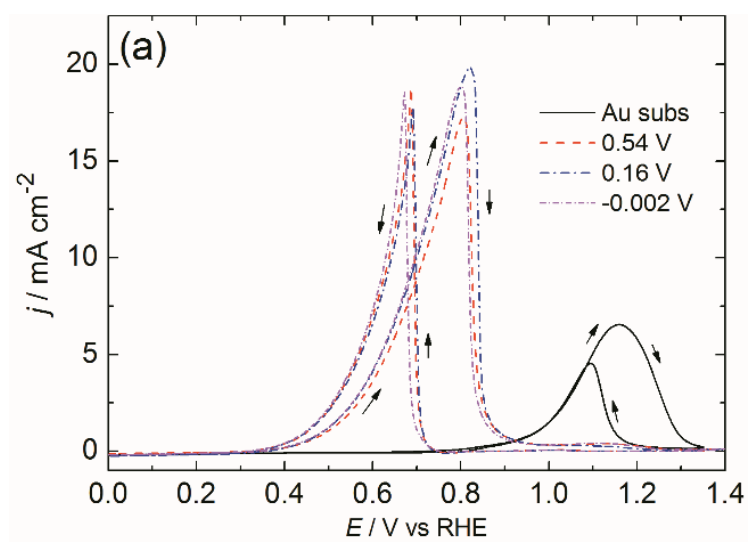




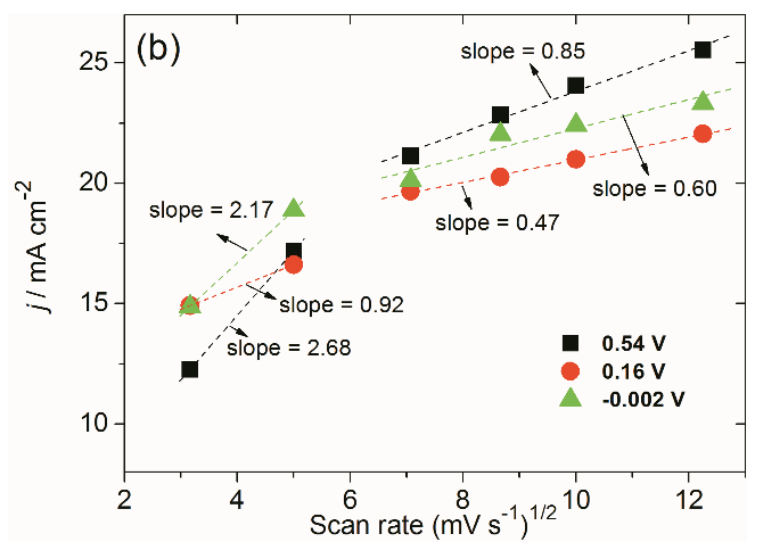

Figure 11. Cyclic voltammetry of Pd NPs deposited on a Au substrate for the electrooxidation of ethanol in deaerated $1 \mathrm{~mol} \mathrm{~L}^{-1}$ ethanol and $0.5 \mathrm{~mol} \mathrm{~L}^{-1} \mathrm{KOH}$ electrolyte. CVs were recorded in static conditions with a scan rate of $25 \mathrm{mV} \mathrm{s}$ 1 (initial/conditioning: $0.4 \mathrm{~V}_{\mathrm{RHE}}, 10 \mathrm{~s}$ ). Each electrode contains total $\mathrm{Pd}$ deposition charge of $3183 \mu \mathrm{C} \mathrm{cm}-2$ (i.e., $1.75 \times 10^{-6} \mathrm{~g} \mathrm{~cm}^{-2}$ ).

The forward peak potential and corresponding peak current density for electrooxidation of ethanol do not vary significantly between the three Pd NPs electrodes. Although, the EASA value for the three Pd NPs electrodes does not differ much, it is generally accepted that a higher EASA would have more active sites for the electrooxidation of ethanol. The highest electrooxidation current obtained for Pd NPs deposited at -0.002 $V_{\text {RHE }}$ corresponded to a specific activity of $12.07 \mathrm{~mA} \mathrm{~cm}^{-2}(\mathrm{Pd})$ followed by $11.54 \mathrm{~mA} \mathrm{~cm}^{-2}(\mathrm{Pd})$ and $10.96 \mathrm{~mA} \mathrm{~cm}^{-2}(\mathrm{Pd})$ for $\mathrm{Pd}$ NPs deposited at $0.16 \mathrm{~V}_{\mathrm{RHE}}$ and $0.54 \mathrm{~V}_{\mathrm{RHE}}$, respectively, as the former electrode has a slightly higher EASA value than the latter. This phenomenon is related with the presence of defect sites on Pd NPs surface as described by Ustarroz et. al. ${ }^{[31]}$

It is known that the electrocatalytic properties of the Pd NPs are influenced by their crystalline structure, particle size and distribution as well as the surface morphology. The normalised specific activities corresponding to the amount of Pd loading is also remarkably high as presented in Table. The enhanced electrocatalytic performance of ethanol electrooxidation mass activity $\left(\approx 10,000 \mathrm{~mA} \mathrm{mg}^{-1}\right)$ of our electrochemically deposited Pd NPs is about 13,10.5, 10.8 and 35 times higher than the corresponding activity reported for $\mathrm{Pd}$ nanoflowers/Ni nanowires electrode $\left(765 \mathrm{~mA} \mathrm{mg}^{-1}\right),{ }^{[29]} \mathrm{Pd}_{45} \mathrm{Pt}_{55}$ nanowires on glassy carbon electrode (950 mA mg-1 ${ }^{-132]} \mathrm{Pd} / \mathrm{rGO} /$ carbon fibre paper (925 mA $\left.\mathrm{mg}^{-1}\right)^{[33]}$ and commercial $\mathrm{Pd}-\mathrm{C} / \mathrm{CFP}\left(286 \mathrm{~mA} \mathrm{mg}^{-1}\right),{ }^{[33]}$, respectively. As the ethanol electrooxidation on the forward scan occurs under diffusion control, the mass transport behaviour on Pd NPs catalysts has been investigated. Figure $11 \mathrm{~b}$ shows the correlation between the peak current density (in the forward scan) and the square root of the scan rate during the electrooxidation process of ethanol at different scan rates. The electrooxidation current of ethanol has a linear relationship at different scan rates with two slope values; the first at lower scan rate with a larger value and the second at higher scan rate with a smaller value. This observation indicates that the electrooxidation process of ethanol on Pd NPs was controlled by concentration polarisation or diffusion processes at higher scan rates of above $25 \mathrm{mV} \mathrm{s}^{-1}$. At lower than $25 \mathrm{mV} \mathrm{s}^{-1}$ scan rate, the electrooxidation was dominated by the activation polarisation of the Pd NPs over the diffusion electrochemistry. The ratio of the forward anodic peak current density $\left(I_{f}\right)$ to the backward anodic peak current density $\left(I_{b}\right)$ is an important index to measure the tolerance to carbonaceous oxidative intermediates accumulated on the catalyst surface during the electrooxidation of ethanol. A high $\mathrm{I}_{\mathrm{f}} / \mathrm{I}_{\mathrm{b}}$ ratio implies the effective oxidation of ethanol to the end products and low accumulation and/or effective elimination of carbonaceous oxidative intermediates on/from the electrocatalyst surface. ${ }^{[28]}$ The $\mathrm{I}_{\mathrm{f}} / \mathrm{l}_{\mathrm{b}}$ ratio of Pd NPs in this work is between 0.86 to 1.05 , comparable with the commercial Pd-C catalyst and other reported values. ${ }^{[33]}$ However, the method developed in this work for electrochemical deposition of highly dispersed Pd NPs could be transferred to alternative substrates, which provide faster electron transfer and mass transport by comparison with the Au substrate of this work enabling catalysts that are more tolerant to oxidative intermediates. After 50 potential cycles, the electrooxidation current for ethanol on the anodic scan had decreased by only $\approx 3.5 \%$, which means that our electrochemically deposited Pd NPs are active and stable catalysts.

\section{Conclusions}

This work investigated the electrochemical deposition of $\mathrm{Pd}$ metallic NPs on $\mathrm{Au}(111)$ substrate in a deaerated $0.1 \mathrm{~mol} \mathrm{~L}^{-1}$ $\mathrm{HCl}$ electrolyte containing $0.001 \mathrm{~mol} \mathrm{~L}^{-1} \mathrm{PdCl}_{2}$ without surfactant and additive effects at small, medium and large overpotential. The effects of the applied overpotential and deposition duration on nucleation, growth, size and morphology of Pd NPs were systematically investigated while other parameters such as precursor concentration and electrolyte $\mathrm{pH}$ were kept constant. A large potential window positive of underpotential deposited hydrogen ( $\mathrm{H}_{\mathrm{UPD}}$ ) was obtained for the electrodeposition of $\mathrm{Pd}$ through the $\mathrm{pH}$ dependent ligand coordination effects of $\mathrm{Cl}^{-}$and $\mathrm{H}_{2} \mathrm{O}$ with $\mathrm{Pd}^{2+}$ ions and, therefore, $\mathrm{Pd} \mathrm{NPs}$ at a specific $\mathrm{pH}$ were deposited with a little influence of the HuPD on growing Pd nuclei. The structural characterisation by means of high resolution FEGSEM revealed that the electrochemical nucleation occurred randomly on $\mathrm{Au}$ substrate when the applied overpotential was small (0.54 $\left.\mathrm{V}_{\mathrm{RHE}}\right)$, medium (0.16 $\left.\mathrm{V}_{\mathrm{RHE}}\right)$ and large (-0.002 $\left.\mathrm{V}_{\mathrm{RHE}}\right)$. At these overpotentials, the randomly nucleated and highly dispersed small nuclei or nanoclusters throughout the surface grew independently by the direct reduction of $\left[\mathrm{PdCl}_{4}\right]^{2-}$ ions towards the complete coverage of the substrate. The synthesised Pd NPs were monodispersed with a hemispherical shape of an average particle size 2-5 nm and highly pure as examined by XPS, thanks to the surfactant-free electrochemical deposition process. The high dispersibility, lack of organic contaminants and small particle size of the Pd NPs resulted in the largest specific surface area (4 times of commercial $\mathrm{Pd}-\mathrm{C}$ ) and demonstrated high electrocatalytic activity in ferrocyanide/ferricyanide redox and ethanol electrooxidation processes. The mass activity $\left(\approx 10,000 \mathrm{~mA} \mathrm{mg}{ }^{-1}\right)$ for ethanol electrooxidation on our electrochemically deposited Pd NPs is 
about 35 times higher than the corresponding activity on commercial Pd-C $\left(286 \mathrm{~mA} \mathrm{mg}^{-1}\right)$ reported to date. ${ }^{[33]}$

\section{Experimental Section}

Materials

$\mathrm{Au}(111)$ textured substrates of $10 \mathrm{~nm}$ thickness was formed by a sputtering process on a $\mathrm{Ti} / \mathrm{SiO}_{2} / \mathrm{Si}$ wafer. The underlying layers of $\mathrm{Ti}$ (10 $\mathrm{nm})$ and $\mathrm{SiO}_{2}(500 \mathrm{~nm})$ were deposited by a similar physical method on $\mathrm{Si}$ wafer to improve the adhesion of $\mathrm{Au}$ and to create an electrical conductivity barrier with the semiconducting $\mathrm{Si}$, respectively. For discussion purposes, we refer to the electrode as a Au substrate only. The wafer was diced into $15 \mathrm{~mm} \times 5 \mathrm{~mm}$ pieces and a diced coupon with the area of $0.6 \mathrm{~cm}^{2}(12 \mathrm{~mm} \times 5 \mathrm{~mm})$ was immersed in the electrolyte for deposition. The remaining $3 \mathrm{~mm}$ at the top of the coupon was left for electrical connection to the potentiostat. Diced $\mathrm{Au}$ electrodes were cleaned in isopropyl alcohol by sonication for 1 hour and dried with $\mathrm{N}_{2}$ gun prior to each of the $\mathrm{Pd}$ deposition experiments. The reagent grade palladium chloride $\left(\mathrm{PdCl}_{2}\right)$, potassium hexacyanoferrate $\left(\mathrm{K}_{3}[\mathrm{FeCN}]_{6}\right)$ and potassium chloride $(\mathrm{KCl})$ were purchased from Sigma Aldrich and used as received. The hydrochloric acid $(\mathrm{HCl})$ of $37 \%$ was purchased from Fisher Scientific and used as received without further purification.

\section{Electrochemical Characterisation}

Cyclic voltammetry (CV) at $5 \mathrm{mV} \mathrm{s}^{-1}$ was employed to study the reduction kinetics of $\left[\mathrm{PdCl}_{4}\right]^{2-}$ from an aqueous electrolyte consisting of $0.01 \mathrm{~mol} \mathrm{~L}^{-1}$ $\mathrm{PdCl}_{2}$ and $0.001 \mathrm{~mol} \mathrm{~L}^{-1} \mathrm{HCl}$. Pt wire and $\mathrm{Ag} / \mathrm{AgCl} /$ saturated $\mathrm{KCl}$ were used as the counter and reference electrode, respectively. The potential measured against the $\mathrm{Ag} / \mathrm{AgCl} /$ saturated $\mathrm{KCl}$ were converted to the reversible hydrogen electrode $(\mathrm{RHE})$ scale using the equation $\mathrm{E}_{\mathrm{RHE}}=$ $\mathrm{E}_{\mathrm{Ag} / \mathrm{AgCl}}+0.059 \times \mathrm{pH}+0.197 \mathrm{~V}$. A potentiostatic method was applied to grow Pd NPs from the same electrolyte at $\mathrm{pH}$ 1.3. The electrode potential was conditioned and equilibrated at an open-circuit potential (OCP) of ca. 0.79 vs. $V_{R H E}$ for $10 \mathrm{~s}$ for each step and then held at the potentials 0.54 $\mathrm{V}_{\mathrm{RHE}}, 0.16 \mathrm{~V}_{\mathrm{RHE}}, 0.06 \mathrm{~V}_{\mathrm{RHE}}$ and $-0.002 \mathrm{~V}_{\mathrm{RHE}}$ for a chosen period (0.2$3600 \mathrm{~s})$. All electrolytes were prepared in milli-Q water $(>18 \mathrm{M} \Omega \mathrm{cm}$ ) and deaerated by nitrogen gas flow for at least 30 minutes in a closed Pyrex electrochemical cell. Followed the electrodeposition, the deposits were promptly rinsed with $18 \mathrm{M} \Omega$ deionised (DI) water and dried in flowing $\mathrm{N}_{2}$. The adsorbed $\left[\mathrm{PdCl}_{4}\right]^{2-}$ ions on the Pd NPs surface were removed during $\mathrm{CV}$ scans, recorded in a $0.1 \mathrm{~mol} \mathrm{~L}^{-1} \mathrm{H}_{2} \mathrm{SO}_{4}$ by cycling the potentials negatively from OCP to $0 \mathrm{~V}_{\mathrm{RHE}}$ with a scan rate of $20 \mathrm{mV} \mathrm{s}^{-1}$ until a steady-state voltammogram was recorded (see Figure S1). The mass of the Pd NPs deposited on the Au electrode surface was estimated from the cathodic charges passed during the electrodeposition obtained from Fig. S2b after subtraction the ions absorption contribution (see Figure $\mathrm{S} 2 \mathrm{c}$ and related discussion). The electrocatalytic performance of the $\mathrm{Pd}$ NPs for ethanol oxidation was determined in a mixture of $0.5 \mathrm{~mol} \mathrm{~L}^{-1} \mathrm{KOH}$ and $1 \mathrm{~mol} \mathrm{~L}^{-1}$ ethanol electrolyte by $\mathrm{CV}$ scanning negatively from $\mathrm{OCP}$ (of ca. $0.4 \mathrm{~V}_{\mathrm{RHE}}$ ) with a scan rate of $25 \mathrm{mV} \mathrm{s}^{-1}$. In this case, Pt wire and $\mathrm{Hg} / \mathrm{HgO} / 1$ mol L $\mathrm{L}^{-1} \mathrm{KOH}$ were used as the counter and reference electrodes, respectively, and the measured potential was converted to $\mathrm{RHE}$ using the following equation $\mathrm{E}_{\mathrm{RHE}}=\mathrm{E}_{\mathrm{Hg} / \mathrm{HgO}}+0.059 \times \mathrm{pH}+0.115 \mathrm{~V}$ (calibrated standard potential of $\mathrm{Hg} / \mathrm{HgOH} / 1 \mathrm{~mol} \mathrm{~L}^{-1} \mathrm{KOH}$ vs. SCE is 0.129 V i.e., $0.244 \mathrm{~V}-0.129 \mathrm{~V}=0.115 \mathrm{~V}$ vs. RHE).

\section{Physical Characterisation}

Scanning Electron Microscopy images were obtained using a high resolution Field Emission Gun-Scanning Electron Microscope (FEGSEM), LEO Gemini 1525. The images were taken at 400K magnification with an extraction voltage of $15 \mathrm{kV}$, a working distance (WD) of $5 \mathrm{~mm}$. According to the specification of the system, the resolution achievable is about $2 \mathrm{~nm}$. Size determination of NPs size analysis were made using freely available software ImageJ.[34] To improve the particle detection, the original FEG-SEM image was convolved with a matrix that is sensitive to the edge of the particle. The convoluted image was then converted to a binary format and analysed by the software using the Particle Analysis function (see Fig. S7 for more details). The composition of the deposits was measured by X-ray Photoelectron Spectroscopy (XPS) using an Al $\mathrm{Ka}(1486.6 \mathrm{eV}) \mathrm{X}$-ray source. XPS data were curve fitted using CasaXPS software using a Shirley background. ${ }^{[35]}$ The $C$ 1s peak was calibrated to $285 \mathrm{eV}$ with the following relative sensitivity factors (R.S.F.): C 1s (1.0), $\mathrm{O}$ 1s (2.93) and Pd 3d (16.0). The UV-visible absorption spectra of the electrolyte were measured on Cary 4000 UV-Vis spectrophotometer (Agilent Technologies) in the range of $300 \mathrm{~nm}$ to $800 \mathrm{~nm}$ equipped with a $1 \mathrm{~cm}$ path length plastic cuvette.

\section{Acknowledgements}

This work was supported by Irish Research Council elevate fellowship co-funded by Marie Curie Actions (Grant: ELEVATEPD/2014/15).

\section{Keywords: Electrodeposition • Palladium • Nanoparticles •} Nucleation • Fuel Cell

[1] a) F.-R. Fan, D.-Y. Liu, Y.-F. Wu, S. Duan, Z.-X. Xie, Z.-Y. Jiang, Z.-Q Tian, J. Am. Chem. Soc. 2008, 130, 6949-6951; b) K. L. McGilvray, C Fasciani, C. J. Bueno-Alejo, R. Schwartz-Narbonne, J. C. Scaiano, Langmuir 2012, 28, 16148-16155; c) C. Burda, X. B. Chen, R. Narayanan, M. A. El-Sayed, Chem. Rev. 2005, 105, 1025-1102; d) A. Henglein, J. Phys. Chem. 1993, 97, 5457-5471.

[2] a) J. Lu, H. Zhang, X. Chen, H. Liu, Y. Jiang, H. Fu, Adv. Synth. Catal. 2013 355, 529-536; b) X.-F. Wu, H. Neumann, M. Beller, ChemSusChem 2013, 6 229-241.

[3] E. R. Krishna, P. M. Reddy, M. Sarangapani, G. Hanmanthu, B. Geeta, K. S. Rani, V. Ravinder, Spectrochimica Acta Part A: Molecular and Biomolecular Spectroscopy 2012, 97, 189-196.

[4] a) G. Berhault, L. Bisson, C. Thomazeau, C. Verdon, D. Uzio, Applied Catalysis A: General 2007, 327, 32-43; b) B. Bridier, D. Karhanek, J. PerezRamirez, N. Lopez, ChemCatChem 2012, 4, 1420-1427.

[5] a) S. B. Kalidindi, H. Oh, M. Hirscher, D. Esken, C. Wiktor, S. Turner, G. Van Tendeloo, R. A. Fischer, Chem. - Eur. J. 2012, 18, 10848-10856; b) F. Ksar, G. K. Sharma, F. Audonnet, P. Beaunier, H. Remita, Nanotechnol. 2011, 22, 305609-305609; c) E. C. Vermisoglou, A. Labropoulos, G. E. Romanos, E. Kouvelos, S. Papageorgiou, G. N. Karanikolos, F. Katsaros, N. K. Kanellopoulos, J. Nanosci. Nanotechnol. 2010, 10, 5971-5980.

[6] a) C.-M. Chang, M.-H. Hon, I.-C. Leu, ACS Appl. Mater. Interfaces 2013, 5, 135-143; b) J.-M. You, H. S. Han, S. Jeon, J. Nanosci. Nanotechnol. 2015, 15, 5691-5698.

[7] W. J. Fang, S. H. Tang, P. X. Liu, X. L. Fang, J. W. Gong, N. F. Zheng, Small 2012, 8, 3816-3822.

[8] a) M. I. Prodromidis, E. M. Zahran, A. G. Tzakos, L. G. Bachas, Int. J. Hydrogen Energy 2015, 40, 6745-6753; b) N. HeYa, Z. Lei, Q. HaiXia, W. Tao, C. MingXi, Y. Nian, L. LingZhi, X. FuBao, G. JianPing, J. Power 
Sources 2015, 288, 160-167; c) M. Shao, J. Power Sources 2011, 196, 24332444; d) E. Antolini, Energy Environ. Sci. 2009, 2, 915-931.

[9] a) O. Verho, T. Akermark, E. V. Johnston, K. P. J. Gustafson, C.-W. Tai, H Svengren, M. D. Karkas, J.-E. Backvall, B. Akermark, Chem. - Eur. J. 2015 21, 5909-5915; b) J. Yang, D. Wang, H. Han, C. Li, Acc. Chem. Res. 2013, 46, 1900-1909; c) R. Su, R. Tiruvalam, A. J. Logsdail, Q. He, C. A. Downing, M T. Jensen, N. Dimitratos, L. Kesavan, P. P. Wells, R. Bechstein, H. H. Jensen, S. Wendt, C. R. A. Catlow, C. J. Kiely, G. J. Hutchings, F. Besenbacher, Acs Nano 2014, 8, 3490-3497.

[10] Z. Aiqin, L. Meng, L. Mi, X. Yuanhua, L. Zhenxing, C. Junli, S. Yuan, Z Jihong, F. Shaoming, J. Dianzeng, L. Feng, J. Mater. Chem. A 2014, 2, 1369 1374.

[11] a) P. C. Pandey, R. Singh, RSC Adv. 2015, 5, 10964-10973; b) M. Ganesan, R. G. Freemantle, S. O. Obare, Chem. Mater. 2007, 19, 3464-3471; c) V Mazumder, S. Sun, J. Am. Chem. Soc. 2009, 131, 4588-4589; d) R. Sato, M Kanehara, T. Teranishi, Small 2011, 7, 469-473; e) V. P. Ananikov, N. V. Orlov, I. P. Beletskaya, V. N. Khrustalev, M. Y. Antipin, T. V. Timofeeva, J. Am. Chem. Soc. 2007, 129, 7252-7253; f) Q. B. Zhang, J. P. Xie, J. H. Yang, J. Y. Lee, Acs Nano 2009, 3, 139-148; g) M. T. Reetz, M. Maase, Adv. Mater. 1999, 11, 773-777.

[12] a) K. R. Brown, D. G. Walter, M. J. Natan, Chem. Mater. 2000, 12, 306-313; b) H. Chen, G. Wei, A. Ispas, S. G. Hickey, A. Eychmueller, J. Phys. Chem. C 2010, 114, 21976-21981.

[13] X. Xia, S. Xie, M. Liu, H.-C. Peng, N. Lu, J. Wang, M. J. Kim, Y. Xia, Proc. Natl. Acad. Sci. U. S. A. 2013, 110, 6669-6673.

[14] a) M. T. Reetz, W. Helbig, J. Am. Chem. Soc. 1994, 116, 7401-7402; b) M. T. Reetz, M. Winter, R. Breinbauer, T. Thurn-Albrecht, W. Vogel, Chem. - Eur. J. 2001, 7, 1084-1094.

[15] a) H. Y. Ma, B. S. Yin, S. Y. Wang, Y. L. Jiao, W. Pan, S. X. Huang, S. H. Chen, F. J. Meng, ChemPhysChem 2004, 5, 68-75; b) B. S. Yin, H. Y. Ma, S Y. Wang, S. H. Chen, J. Phys. Chem. B 2003, 107, 8898-8904; c) S. X. Huang, H. Y. Ma, X. K. Zhang, F. F. Yong, X. L. Feng, W. Pan, X. N. Wang, Y. Wang, S. H. Chen, J. Phys. Chem. B 2005, 109, 19823-19830; d) W. Pan, X. Zhang, H. Ma, J. Zhang, J. Phys. Chem. C 2008, 112, 2456-2461.

[16] M. L. Rodriguez-Sanchez, M. J. Rodriguez, M. C. Blanco, J. Rivas, M. A. Lopez-Quintela, J. Phys. Chem. B 2005, 109, 1183-1191.

[17] M. Rezaei, S. H. Tabaian, D. F. Haghshenas, Electrochim. Acta 2012, 59, 360 366.
[18] a) A. J. Bard, L. R. Faulkner, Electrochemical Methods: Fundamentals and Applications, John Wiley \& Sons, Inc., New York, 2002; b) M. Rezaei, S. H. Tabaian, D. F. Haghshenas, Electrochim. Acta 2013, 87, 381-387; c) N. A. Al Abass, G. Denuault, D. Pletcher, Phys. Chem. Chem. Phys. 2014, 16, 4892 4899.

[19] a) H. Naohara, S. Ye, K. Uosaki, J. Electroanal. Chem. 2001, 500, 435445; b) H. Naohara, S. Ye, K. Uosaki, J. Electroanal. Chem. 1999, 473 2-9; c) H. Naohara, S. Ye, K. Uosaki, J. Phys. Chem. B 1998, 102 4366-4373.

[20] L. I. Elding, L. F. Olsson, J. Phys. Chem. 1978, 82, 69-74.

[21] L. Espinosa-Alonso, K. P. de Jong, B. M. Weckhuysen, Phys. Chem. Chem. Phys. 2010, 12, 97-107.

[22] M. Baldauf, D. M. Kolb, J. Phys. Chem. 1996, 100, 11375-11381.

[23] G. Denuault, C. Milhano, D. Pletcher, Phys. Chem. Chem. Phys. 2005, 7, 3545-3551.

[24] S. Cherevko, N. Kulyk, C. H. Chung, Nanoscale 2012, 4, 103-105.

[25] C. T. Hsieh, Y. Y. Liu, Y. S. Cheng, W. Y. Chen, Electrochim. Acta 2011, 56, 6336-6344.

[26] F. Ksar, G. Surendran, L. Ramos, B. Keita, L. Nadjo, E. Prouzet, P. Beaunier, A. Hagege, F. Audonnet, H. Remita, Chem. Mater. 2009, 21, 1612-1617.

[27] G. Surendran, F. Ksar, L. Ramos, B. Keita, L. Nadjo, E. Prouzet, P. Beaunier, P. Dieudonne, F. Audonnet, H. Remita, J. Phys. Chem. C 2008, 112, 1074010744

[28] R. Manoharan, J. B. Goodenough, J. Phys. Chem. 1992, 2, 875-887.

[29] M. Hasan, S. B. Newcomb, J. F. Rohan, K. M. Razeeb, J. Power Sources 2012 218, 148-156.

[30] Z. X. Liang, T. S. Zhao, J. B. Xu, L. D. Zhu, Electrochim. Acta 2009, 54, 2203-2208.

[31] J. Ustarroz, X. Ke, A. Hubin, S. Bals, H. Terryn, J. Phys. Chem. C 2012, 116, 2322-2329.

[32] C. Zhu, S. Guo, S. Dong, Adv. Mater. 2012, 24, 2326-2331.

[33] M. Sawangphruk, A. Krittayavathananon, N. Chinwipas, J. Mater. Chem. A 2013, 1, 1030-1034

[34] C. A. Schneider, W. S. Rasband, K. W. Eliceiri, Nat. Methods 2012, 9, 671-675.

[35] L. Ley, D. A. Shirley, R. Pollak, S. Kowalczy, Phys. Rev. Lett. 1972, 29, 1088-1092. 


\section{ARTICLE}

Scalable electrochemical synthesis of low dimension Pd nanoparticles (Pd NPs) of below $5 \mathrm{~nm}$ with clean surface and high dispersity from a surfactant-free green electrolyte is demonsatrted. The synthesised Pd NPs demonstrated the largest specific surface area (4 times of commercial $\mathrm{Pd}-\mathrm{C}$ ) and the electrocatalytic activity in ferrocyanide/ferricyanide redox and ethanol electrooxidation processes (35 times of $\mathrm{Pd}-\mathrm{C}$ ).
$\operatorname{Dr}$ M. Hasan, * Dr W. Khunsin C. K. Mavrokefalos, Prof. S. A. Maier, Dr. J. F. Rohan, Prof. J. S. Foord

Page No. 1-13.

((Insert TOC Graphic here))
Facile Electrochemical Synthesis of Pd Nanoparticles with Enhanced Electrocatalytic Properties from Surfactant-Free Electrolyte 